\title{
Estimation of the joint roughness coefficient of rock joints by consideration of two-order asperity and its application in double-joint shear tests
}

\author{
Xige Liu, Wancheng Zhu*, Qinglei Yu, Shijiang Chen, Rufei Li \\ Center for Rock Instability and Seismicity Research and Key Laboratory of Ministry of Education on Safe Mining \\ of Deep Metal Mines, Northeastern University, Shenyang, 110819, China \\ Institute of Mining Research, Inner Mongolia University of Science and Technology, Baotou, 014010, People's \\ Republic of China
}

\begin{abstract}
Joint roughness has a significant influence on the shear behavior of rock joints. Many different statistical parameters have been used to estimate the joint roughness coefficient $(J R C)$ of rock joints, depending on what is most easily available and convenient. Six statistical parameters, $\mathrm{Z}_{2}, \mathrm{SF}, \mathrm{R}_{\mathrm{P}}-1, \log \left(\mathrm{Z}_{2}\right), \operatorname{logSF}$ and $\sqrt{R_{P}-1}$ of ten typical roughness profiles at different sampling intervals $(S I)$. The results indicate that the $J R C$ of rock joints could not be accurately estimated by using only a single statistical parameter. Because the first-order and second-order asperities of joints have different effects on the shear behavior, a classified and weighted method fitting formula, $J R C=16.09 \log \mathrm{Z}_{2}{ }^{1 \mathrm{st}}+12.70 \log \mathrm{Z}_{2}{ }^{2 \text { nd }}+33.75(S I=5.0 \mathrm{~mm} \& 0.5 \mathrm{~mm})$, is proposed to estimate $J R C$ of the rock joints. Shear tests on sandstone joints indicate that the maximum $J R C$ along the shear direction is appropriate to represent the total joint surface and estimate the shear strength. This formula was adopted to estimate the $J R C$ in double-joint shear tests, and the results show that the mechanical behavior of double parallel joints is closely relared to the interlayer rock and the weaker joint. Under lower normal stress, the interlayer rock does not fracture, and the weaker joint determines the peak shear strength of the rock specimen. In contrast, under higher normal stress, the peak shear strength is attained when the tensile fractures initiate in the interlayer rock, and it has also relevancy to the $J R C$ of double joints and interlayer thickness.
\end{abstract}

Keywords: statistical parameter, joint roughness coefficient $(J R C)$, roughness profile, shear test, parallel joints, shear strength

\section{Abbreviations:}

$D$ Fractal dimension (dimensionless)

\footnotetext{
* Corresponding author, Tel.: +86-24-83687705; fax: +86-24-83681186, zhuwancheng@mail.neu.edu.cn
} 
$J R C$

$P_{0}(0.5)$

$P_{1}(5.0)$

$P_{2}(0.5)$

$R \mathrm{p}$

$R \mathrm{p}^{1 \mathrm{st}}, R \mathrm{p}^{2 \mathrm{nd}}$

SSE

SF

$S F^{1 \mathrm{st}}, S F^{2 \mathrm{nd}}$

SI

$T$

$x_{\mathrm{i}}, y_{\mathrm{i}}$

$Z_{2}$

$Z_{2}^{1 \text { st }}, Z_{2}^{2 \text { nd }}$

$\sigma_{\mathrm{c}}$

$\sigma_{\mathrm{n}}$

$\tau_{\text {peak }}$
Length of joint surface $(\mathrm{mm})$

Joint roughness coefficient (dimensionless)

Original roughness profile containing both the first-order and second-order asperities, $S I=0.5 \mathrm{~mm}$

Roughness profile containing the first-order asperities only, $S I=5.0 \mathrm{~mm}$,

Roughness profile containing the second-order asperities only, $S I=0.5 \mathrm{~mm}$,

Roughness profile index (dimensionless)

$\mathrm{Rp}$ of the first-order and second-order asperities, respectively (dimensionless)

Sum of squared error (dimensionless)

Structure function $\left(\mathrm{mm}^{2}\right)$

SF of the first-order and second-order asperities, respectively $\left(\mathrm{mm}^{2}\right)$

Sampling interval of a roughness profile $(\mathrm{mm})$

Thickness of the interlayer rock in a rock sample with double parallel joints (mm)

Coordinate values of a roughness profile $(\mathrm{mm})$

Root mean square of the first deviation of the profile (dimensionless)

$\mathrm{Z}_{2}$ of the first-order and second-order asperities, respectively (dimensionless)

Uniaxial compressive strength of rock (MPa)

Normal stress of a rock sample (MPa)

Peak shear stress (MPa)

\section{Introduction}

Many studies have been performed to determine the relationship between the joint roughness and shear behavior. Of these approaches, Eq.1 is widely used and was proposed by Barton (1973) to estimate the peak shear strength of rock joints,

$$
\tau=\sigma_{n} \tan \left[J R C \log \left(\frac{J C S}{\sigma_{n}}\right)+\varphi_{b}\right]
$$

where $\tau$ is the peak shear strength of the rock joint, $\sigma_{\mathrm{n}}$ is the effective normal stress, $J R C$ is the joint roughness coefficient, JCS is joint wall compressive strength, which is equal to the uniaxial compressive strength (UCS) of the rock for the fresh rock joints, and $\varphi_{\mathrm{b}}$ is the basic friction angle. Ten typical profiles were defined for typical 
JRC values by visual assessment (Barton and Choubey, 1977). This method was recommended by the International Society for Rock Mechanics (ISRM) commission on test methods (IRSM, 1978) and this quantitative estimation of $J R C$ values has been extensively studied for decades.

Along the shear direction, the joint profile can be determined by using a profile comb. Based on the coordinate values $\left(x_{\mathrm{i}}, y_{\mathrm{i}}\right)$ of a joint profile, a series of parameters to quantify the joint profile have been defined, and among them, $Z_{2}, S F$, and $R_{\mathrm{P}}$ are the most commonly used ones. The root mean square of the first deviation of the profile, $Z_{2}$, was proposed by Myers (1962) in 1962; the structure function, $S F$, was proposed by Sayles and Thomas (1977) in 1977; the ratio of the true length of a fracture surface trace to its projected length, $R_{\mathrm{P}}$ was proposed by El-Soudani (1978). Their definitions are as follows:

$$
\begin{aligned}
& Z_{2}=\left[\frac{1}{L} \int_{x=0}^{x=L}\left(\frac{d y}{d x}\right)^{2} d x\right]^{1 / 2}=\left[\frac{1}{L} \sum_{i=1}^{n-1} \frac{\left(y_{i+1}-y_{i}\right)^{2}}{x_{i+1}-x_{i}}\right]^{1 / 2}, \\
& S F=\frac{1}{L} \int_{x=0}^{x=L}[f(x+d x)-f(x)]^{2} d x=\frac{1}{L} \sum_{i=1}^{n-1}\left(y_{i+1}-y_{i}\right)^{2}\left(x_{i+1}-x_{i}\right), \\
& R_{P}=\frac{1}{L} \sum_{i=1}^{n-1}\left[\left(x_{i+1}-x_{i}\right)^{2}+\left(y_{i+1}-y_{i}\right)^{2}\right]^{1 / 2} .
\end{aligned}
$$

where $L$ is the length of the joint profile, and $x_{\mathrm{i}}$ and $y_{\mathrm{i}}$ are coordinates of the joint profile.

Next, these indexes were related to $J R C$. The regression correlations between $Z_{2}$ and $S F$ with $J R C$ values were established by Tse and Cruden (1979), and Eq.5, Eq.6, and $R_{\mathrm{P}}$ was used by Maerz et al. (1990) , Eq.7.

$$
\begin{aligned}
& J R C=32.2+32.47 \log Z_{2} \\
& J R C=37.28+16.58 \log S F \\
& J R C=411\left(R_{\mathrm{P}}-1\right)
\end{aligned}
$$

However, the validity of the estimation of $J R C$ based on roughness parameters remains under debate, because parameters $Z_{2}, S F$, and $R_{\mathrm{P}}$ and their variants are sensitive to the sampling interval (SI) of roughness profiles. Yu and Vayssade (1991) found that $Z_{2}$ and $S F$ changed for sampling intervals of $0.25 \mathrm{~mm}, 0.5 \mathrm{~mm}$, or $1.0 \mathrm{~mm}$, suggesting that the coefficients of these fitting formulas must be changed for different sampling intervals. However, Yang et al. (2001a) questioned the conclusions from Tse and Cruden's (1979) work because enlarging $10 \mathrm{~cm}$ profiles by 2.5 times resulted in self-transformation, and they proposed fitting formulas of $J R C$ with modified coefficients. Jang et al. (2014) noted that $Z_{2}$ and $R_{\mathrm{p}}$ decreased as the sampling interval increased, but the $S F$ values increased very rapidly as the sampling interval increased. Additionally, other parameters, such as the fractal dimension $D$, and $\theta_{\max }{ }^{*} /(C+1)_{2 \mathrm{D}}$, which could also be used to quantify the $J R C$ values, but are all 
associated with sampling interval (Tatone and Grasselli, 2010; Jang, 2014). Thus, it is imperative to consider sampling interval in accurate estimations of $J R C$.

The asperity of a rough joint can occur on many scales. As early as 1966, Patton (1966) classified the asperity of rough joints into first-order (waviness) and second-order (unevenness) categories, and reported that the shear behavior of rock joints was primarily controlled by second-order and first-order asperity during small and large displacements, respectively. This viewpoint was later supported by Barton (1973) and Hoek et al. (1981). who found that second-order asperity controlled the shearing process under lower normal stress. However, under higher normal stress, the shearing process was controlled mainly by first-order asperity. Because the $J R C$ is widely adopted in engineering practice, it is quite important to relate the asperity categories and JRC. Yang et al. (2001b) conducted shear tests to clarify the effect of asperity order on the roughness of artificial rock joints, and concluded by combining the $J R C$ and Hurst exponent $H$ (or fractal dimension $D$ ) allowed a more accurate description of roughness behavior due to multi-scale asperities. Chen et al. (2012) used fractal dimension $D$ and the degree of waviness $w_{\mathrm{d}}$ to estimate the $J R C$, but the parameter $w_{\mathrm{d}}$ may omit important information especially for a long roughness profile. Additionally, the best way to quantify the first-order and the second-order asperities are quantified to estimate the $J R C$ remains unclear.

In most studies of shear tests on rock joints, only a single joint was tested, and these studies confirms that the $J R C$ has an important influence on the peak shear strength of rock joints. However, in real rockmass, adjacent joints may interact with each other, and therefore, the shear behavior of double rock joints may very different from that of a single joint. In this respect, systematic experiments are still needed in order to understand the shear behavior of double rock joints under the influence of $J R C$ values.

In this paper, first, the ten typical roughness profiles were decomposed into two classes of new profiles that separately contain the first-order and second-order asperities. Second, the statistical parameters of the two classes of new profiles were weighted in a series of fitting formulas to estimate $J R C$ values; and then, the best one was selected and verified during the shear tests. Finally, this approach was used to estimate $J R C$ and the peak shear strength during the shear tests of double parallel joints.

\section{Correlation between the statistical parameters and sampling interval}

By using the statistical parameters to estimate the $J R C$ of rock joints, any sampling interval would omit some information below a certain threshold. Typically, sampling intervals between $0.1 \mathrm{~mm}$ to $2 \mathrm{~mm}$ are used. In this study, the ten typical profiles were retrieved using a sampling interval from $0.25 \mathrm{~mm}$ to $10 \mathrm{~mm}$. 
In order to calculate the statistical parameters of the ten typical roughness profiles, the coordinate values $\left(x_{\mathrm{i}}\right.$, $y_{\mathrm{i}}$ ) are essential elements. To do this, the image of the joint profiles was imported into the AutoCAD software. The profiles were scaled to $10 \mathrm{~cm}$ in length and traced them with the command "polyline"; each generated polyline contains more than four hundred of points ( the original $S I \leq 0.25 \mathrm{~mm}$ ) to accurately duplicate the original roughness profiles well. Next, the polylines that represent the joint profile were sampled and their coordinates of sampling points were imported into a MATLAB programme written by ourselves, in which the roughness profiles were redrawn at a certain sampling interval, such as $0.5 \mathrm{~mm}$. As a result, the new roughness profiles were composed of a series of equally spaced points. Based on the coordinates of these points, the statistical parameters $\left(Z_{2}, S F, R_{\mathrm{P}-1}\right.$ and three typical types of their variations $\log Z_{2}, \log S F$, and $\left.\sqrt{R_{P}-1}\right)$ were calculated at different sampling intervals, and the results are shown in Fig. 1.

[Fig. 1 goes here]

From Fig.1, it could be found that the statistical parameters increased with the increased sequence numbers of these profiles. However, when the sampling interval was less than $1 \mathrm{~mm}$, almost all of the six parameters tended to decrease between the $4^{\text {th }}$ and $6^{\text {th }}$ roughness profiles, which is consistent with the result calculated by Chen et al. (2012) using fractal dimension $D$. In addition, when the sampling interval was larger than $1 \mathrm{~mm}$ the six parameters tended to decline between the $8^{\text {th }}$ and $9^{\text {th }}$ roughness profiles, with other fluctuations. In practice, the $J R C$ values given by Barton are increase approximately in a straight line, as shown in Fig. 2. From this perspective, this trend of the six statistical parameters occurs only at the sampling interval of $1 \mathrm{~mm}$. Even so, as shown in Fig.1, there are little obvious differences between the $4^{\text {th }}, 5^{\text {th }}$, and $6^{\text {th }}$ roughness profiles at a same sampling interval of $1 \mathrm{~mm}$. Therefore, it is not reasonable to estimate the $J R C$ by using a single statistical parameter.

[Fig. 2 goes here]

\section{Estimation of $J R C$ by weighting the first-order and second-order asperities}

The first-order and second-order asperities play different roles during the shearing process, and make different contributions to the shear strength. Therefore, the $J R C$ can be estimated by classifying and weighting the statistical parameters based on the effects of the first-order and second-order asperities.

The ten typical roughness profiles were redrawn at two different sampling intervals (SIs) with the same method as described in Section 2. The gap between the two SIs is an order of magnitude, e.g., SI=5.0mm and 
$S I=0.5 \mathrm{~mm}$, where $5.0 \mathrm{~mm}$ represents first-order asperity and $0.5 \mathrm{~mm}$ represents the second-order asperity. Next, the abscissas $\left(x_{\mathrm{i}}\right)$ were kept constant and the ordinates $\left(y_{\mathrm{i}}\right)$ of the redrawn profiles were subtracted at larger $S I$ from those at smaller $S I$. Fig. 3 a shows the $10^{\text {th }}$ typical roughness profile redrawn at $S I=0.5 \mathrm{~mm}, P_{0}(0.5)$, which should contain both the first-order and second-order asperities, and the profile at $S I=5 \mathrm{~mm}, P_{1}(5)$, should contain the first-order asperity only, as shown in Fig. 3b. By subtracting the ordinate ( $\left.y_{\mathrm{i}}\right)$ of Fig. $3 \mathrm{~b}$ from Fig. 3a, we can obtain the profile for the second-order asperity only, $P_{2}(0.5)$, as shown in Fig.3c. Finally, statistical parameters of the classified roughness profiles that are composed of a series of equally spaced points can be calculated at different sampling intervals.

[Fig. 3 goes here]

Fig.4. shows the classified statistical parameters of $P_{0}(0.5), P_{1}(5.0)$, and $P_{2}(0.5)$ of the ten typical roughness profiles. Although the overall trend of the six statistical parameters is still increasing, significant difference appears between $P_{1}(5.0)$ and $P_{2}(0.5)$ as the sequence numbers increase. For instance, $Z_{2}$ (Fig. 4a) decreases between the $4^{\text {th }}$ and $6^{\text {th }}$ roughness profiles for $P_{2}(0.5)$ but increases for $P_{1}(5.0)$. The opposite tendency is seen for the $8^{\text {th }}$ roughness profile. This result confirms that the $4^{\text {th }}$ roughness profile contains many second-order asperities but lacks the first-order ones. The opposite is true for the $6^{\text {th }}$ and the $8^{\text {th }}$ roughness profiles. With slight differences, the same phenomenon also occurs for the other 5 statistical parameters, $S F, R_{\mathrm{P}-1}, \log Z_{2}, \log S F$, and $\sqrt{R_{P}-1}$. Therefore, it is more reasonable to estimate the $J R C$ by decomposing the typical roughness profiles into the first-order and the second-order asperities.

[Fig. 4 goes here]

On the basis of first-order and second-order asperities of the roughness profiles, the statistical parameters have also been divided into two classes, for instance, $Z_{2}$ is decomposed into $Z_{2}{ }^{1 \text { st }}$ and $Z_{2}{ }^{2 \text { nd }}$, which represent the first-order and second-order asperities, respectively. For comparison, in addition to the sampling interval combination of $5.0 \mathrm{~mm}$ and $0.50 \mathrm{~mm}$, those of $2.5 \mathrm{~mm}$ and $0.25 \mathrm{~mm}$ and $10.0 \mathrm{~mm}$ and $1.0 \mathrm{~mm}$ were also examined.

Next, a series of classified and weighted fitting formulas of $J R C$ were obtained, by using the least square method. These formulas contain two parameters that represent the first-order and second-order asperities. To determine the best formula and to compare with the results estimated by the fitting formulas containing a single statistical parameter, the sum of squared error $(S S E)$ was used for quantitative comparison, rather than the commonly used correlation coefficient, because at least two correlated variables were included in the new fitting formulas. As listed in Table 1, the smaller the SSE is, the better fitting effect it achieves. 
[Table 1 goes here]

$$
\begin{array}{ll}
J R C=75.11 Z_{2}^{1 \mathrm{st}}+3.33 Z_{2}^{2 \mathrm{nd}}-2.79 & (S I=2.5 \mathrm{~mm} \& 0.25 \mathrm{~mm}) \\
J R C=91.73 S F^{1 \mathrm{st}}-57.13 S F^{2 \mathrm{nd}}+3.89 & (S I=2.5 \mathrm{~mm} \& 0.25 \mathrm{~mm}) \\
J R C=472.16\left(R_{\mathrm{P}-}-1\right)^{1 \mathrm{st}}-20.42\left(R_{\mathrm{P}}-1\right)^{2 \mathrm{nd}}+3.32 & (S I=2.5 \mathrm{~mm} \& 0.25 \mathrm{~mm}) \\
J R C=16.09 \log Z_{2}^{1 \mathrm{st}}+12.70 \log Z_{2}^{2 \mathrm{nd}}+33.75 & (S I=5.0 \mathrm{~mm} \& 0.50 \mathrm{~mm}) \\
J R C=11.32 \log S F^{1 \mathrm{st}}+5.79 \log S F^{2 \mathrm{nd}}+34.17 & (S I=2.5 \mathrm{~mm} \& 0.25 \mathrm{~mm}) \\
J R C=108.12{\sqrt{R_{P}-1}}^{1 \mathrm{st}}+6.31{\sqrt{R_{P}-1}}^{2 \mathrm{nd}}-3.66 & (S I=2.5 \mathrm{~mm} \& 0.25 \mathrm{~mm})
\end{array}
$$

Obviously, from Table 1, the classified and weighted fitting formulas are better than those containing a single parameter only. For the six statistical parameters, the minimum SSE were derived from the classified and weighted fitting formulas, and Eq.8 to Eq.13 list the best fitting formulas for each statistical parameter. To obtain highly accurate $J R C$ values by using Eq.8 to Eq.13, it is imperative to use the right sampling interval combination. Specifically, $Z_{2}, S F, R_{\mathrm{P}}-1, \log S F$, and $\sqrt{\mathrm{R}_{\mathrm{P}}-1}$ exhibit minimum $\mathrm{SSE}$ at $S I=2.5 \mathrm{~mm} \& 0.25 \mathrm{~mm}$, but the $\log Z_{2}$ shows the minimum $S S E$ at $S I=5.0 \mathrm{~mm} \& 0.50 \mathrm{~mm}$, and it is the lowest of all SEEs.

Thus, the classified and weighted fitting formula of $\log Z_{2}$ (Eq.11) is the most accurate for estimating $J R C$. The $J R C$ values given by Barton and Choubey (1977) and those estimated by using Eq.11 are illustrated in Fig.2. Although the $4^{\text {th }}$ roughness profile is slightly overestimated and the $9^{\text {th }}$ one is slightly underestimated, the other points match reasonably well.

The graphics of classified and weighted JRC fitting formulas are planes or surfaces, as shown in Fig.5. Specifically, the fitting graphics of $Z_{2}, S F, R_{\mathrm{P}}-1$ are planes, and those of $\log Z_{2}, \log S F$, and $\sqrt{R_{P}-1}$ are surfaces. As shown in Fig.5, better fitting means that the points representing $J R C$ of the ten typical roughness profiles are all on, or very near the planes or surfaces. Obviously, the surfaces are better than the planes, i.e. the fitting effect of $\log Z_{2}, \log S F$, and $\sqrt{R_{P}-1}$ is better than those of $Z_{2}, S F$, and $R_{\mathrm{P}^{-}} 1$, respectively, consistent with the results of Table 1.

[Fig. 6 goes here]

\section{Verification of the classified and weighted method with shear tests}

In order to verify the classified and weighted method for estimating $J R C$, direct shear tests were performed on 5 pairs of sandstone specimens under different normal loading. The mechanical parameters of the sandstone 
are listed in Table 2. The size of these specimens is $10 \mathrm{~mm} \times 10 \mathrm{~mm}$, as shown in Fig. 6 , they are generated by a method similar to the Brazilian Split test, and thus, the lower-half joint surface and the upper one match well.

[Table 2 goes here]

[Fig. 6 goes here]

[Fig. 7 goes here]

By using the 3D scanning system (Comet L3D), the 3D image of the rock joint surface was retrieved, as shown in Fig. 7. By cutting the profiles along the shear direction, a series of roughness profiles of the joint surface can be obtained. Ten roughness profiles were cut for each joint surface, at a spacing of 9mm (Fig. 7). The $J R C$ values of these 5 joints were calculated with Eq.11 and were also estimated with the classical formula given by Tse and Cruden (1979) for comparison, Eq.5.

The calculated results are shown in Table 3. For the 5 sandstone specimens, the average, maximum and minimum $J R C$ values calculated by Eq.11 are all a little smaller than those calculated by Eq.5, but the gap between the maximum and minimum $J R C$ values calculated by Eq.11 are all larger than those calculated by Eq.5. It is worth mentioning that the minimum $J R C$ values calculated by Eq.11 and Eq.5 for the sample No.2 were not based on the same roughness profile, showing the obvious difference between these two equations.

[Table 3 goes here]

Direct shear tests were conducted on the 5 sandstone specimens under normal loading of $5 \% \sigma_{c}, 10 \% \sigma_{c}$, $15 \% \sigma_{\mathrm{c}}, 20 \% \sigma_{\mathrm{c}}$, or $30 \% \sigma_{\mathrm{c}}$, respectively, where $\sigma_{\mathrm{c}}$ is the uniaxial compressive strength of the sandstone, and the shear rate is fixed at $5 \mathrm{~mm} / \mathrm{min}$. Fig. 8 shows the shear stress - displacement curves of the 5 sandstone specimens, and the peak shear strengths were compared with the ones estimated by Barton's empirical equation (Eq.1), as listed in Table 4. The sum of the squared errors (SSE) was used as a criterion for comparison. The smaller the SSE is, the better the estimation of $J R C$. In Table 4, the estimated peak shear strength of the 5 sandstone specimens exhibited the smallest SSE, i.e. the best estimation effect, by using Eq.11 with the maximum $J R C$ values. The next best were those calculated using Eq.5 with maximum $J R C$ values.. Furthermore, Table 5 shows the $J R C$ values back-calculated with Eq.1 and the estimated ones according to the Eq.11 and Eq.5, respectively. As shown above, the maximum $J R C$ values calculated with Eq.11 are the most consistent with the experimental results when they are used to estimate the peak shear strength according to Eq.1.

[Fig. 8 goes here]

[Table 4 goes here] 
[Table 5 goes here]

Previous experiments indicated that only a small fraction of the joint surface area was damaged during shearing. In this study, Fig.9 shows the two halves of specimen No.2 after the shear test under normal loading of $10 \% \sigma_{\mathrm{c}}$. The white area play the main role during shearing and contribute the majority of shear resistance. Similarly, in the 3D image of the rock joint, the main sheared area is in high elevation and the joint surface profile through this area shows the maximum $J R C$. Thus, it is appropriate to use the maximum $J R C$ to estimate the peak shear strength, and these results match well with the experimental results.

[Fig. 9 goes here]

[Table 6 goes here]

Because the maximum $J R C$ value is the most suitable to estimate the peak shear strength, it is necessary to verify whether the roughness profile spacing is sufficiently enough to get the maximum $J R C$ value. Actually, the maximum $J R C$ value of joint surface is difficult to obtain from 2D roughness profile lines, but it can be approximated by gradually reducing the profile spacing. The sandstone specimen size in this shear tests is $10 \mathrm{~mm} \times 10 \mathrm{~mm}$, and 10 roughness profiles were used to calculate the $J R C$ with a profile spacing of $9 \mathrm{~mm}$. For comparison, $18 \mathrm{~mm}$ and $4.5 \mathrm{~mm}$ were also used as the profile spacing to cut the digital joint surface, and the calculated $J R C$ values are shown in Table 6. We considered that if the relative tolerance between two profile spacings was less than $5 \%$, the lager profile spacing would be acceptable from the viewpoint of practical convenience. Table 6 indicates that the profile spacing of $9 \mathrm{~mm}$ is suitable in this study, but $18 \mathrm{~mm}$ does not achieve maximum $J R C$ values and $4.5 \mathrm{~mm}$ is not necessary.

\section{Application of new JRC estimation in double-joint shear test}

The mechanical behavior of multiple joints has been studied (e.g. Yang et al., 1998; Jiang et al., 2015), but few of these studies have focused on the influence of $J R C$. In this section, using the classified and weighted method for estimating $J R C$, direct shear tests on sandstone specimens containing double parallel joints were performed. The $J R C$ of each joint was calculated by Eq.11 and its peak shear strength is estimated by Eq.1. The sectional dimension of the joint samples was $10 \mathrm{~mm} \times 10 \mathrm{~mm}$, Fig 10 . The rough joints were generated by a method similar to the Brazilian Split tests and the smooth joints were generated by being sawed-off.

\subsection{Experimental design}

Direct shear tests of double parallel rock joints were performed under the CNL (constant normal loading) 
condition, Fig 10. The normal stress are $5 \% \sigma_{\mathrm{c}}, 15 \% \sigma_{\mathrm{c}}$, or $25 \% \sigma_{\mathrm{c}}$ were applied on the samples at a rate of $0.5 \mathrm{KN} / \mathrm{s}$. The shear stress was applied by fixing the lower shear box and pushing the upper one at a rate of $5 \mathrm{~mm} / \mathrm{min}$. Average thicknesses of the interlayer rock were $10 \mathrm{~mm}, 20 \mathrm{~mm}$ and $40 \mathrm{~mm}$ (accuracy was guaranteed by using both the Brazilian Split method and sawed-off method). The lower and upper pieces were both 50mm thick. Three types of roughness combinations were adopted in the double-joint shear tests, smooth-smooth joints (S-S joints), rough-smooth joints (R-S joints) and rough-rough joints (R-R joints). The specific experimental design is shown in Fig 11, and these specimens were all intact under normal loading conditions $\left(5 \% \sigma_{c}, 15 \% \sigma_{c}\right.$, or $\left.25 \% \sigma_{c}\right)$ before shearing.

[Fig. 10 goes here]

[Fig. 11 goes here]

\subsection{Experiment results}

\subsubsection{Shear stress - shear displacement curves}

Similar to the experimental results of the single joint shear test, the shear stress - shear displacement curves are plotted for the double-joint shear tests, as shown in Fig.12. It is worth noting that both the shear stress and shear displacement reflect the overall response of double joints. For comparisons, the peak shear strength of the single smooth joint $(J R C=0.4)$ was estimated by using Eq.1 and that of the weaker joint of an R-R joints, i.e., the peak shear strength of joints with $J R C$ of 13.6, 8.1, and 11.0 were calculated according to Eq.1 under normal stress of $5 \% \sigma_{\mathrm{c}}, 15 \% \sigma_{\mathrm{c}}$ or $25 \% \sigma_{\mathrm{c}}$. The shear results of single smooth joints are also shown in Fig.12.

[Fig. 12 goes here]

Fig.12a shows the shear results under the normal loading of $\sigma_{\mathrm{n}}=5 \% \sigma_{\mathrm{c}}$. The peak shear strengths of the S-S joints, R-S joints, single smooth joint and estimated ones by using Eq.1 are all very close, which indicates that the peak shear strength of double parallel joints is dominated by the weaker one under the lower normal stress condition. Fig. 13 shows the failure process of sandstone samples containing double parallel joints: all the samples were sheared off along one joint only. Even for the S-S joints, although there is a very slight difference in roughness between the two smooth joints, it slides along the smoother one.

Remarkably, for the R-R joints, the experimental peak shear strength was $24.5 \%$ higher than the estimated one. This phenomenon may be common because for the $40 \mathrm{~mm}$ thick interlayer rock, both the upper and lower surfaces are rough and torsion is induced in the interlayer when shearing. This further induce additional normal 
stress. In general, the normal stress fluctuation of the servo pressure control system is around $1 \pm 3 \%$, but it jumps to $1+8 \%$ for these double-joint shear tests, thus suggesting the complex stress condition that is induced during the double-joint shear tests.

Fig.12b and Fig.12c show the shear stress - shear displacement curves of the double-joint shear tests under normal loading of $\sigma_{\mathrm{n}}=15 \% \sigma_{\mathrm{c}}$ and $\sigma_{\mathrm{n}}=25 \% \sigma_{\mathrm{c}}$, respectively. Fig.14 and Fig. 15 show their shear failure patterns. As normal stress increased, the peak shear stress tended to be lower than that of the weaker joint, because of the damage and failure of interlayer rock. At the same time, the influence of interlayer thickness also appears, as shown in the Fig.14 and Fig.15. When the interlayer rock becomes thicker, the dominant vertical tensile crack is more likely to be induced, which leads to a decrease of peak shear strength of the combined specimen. Additionally, under the same interlayer thickness, the peak shear strength of S-S joints is obviously lower than the strength of R-R joints with the same interlayer thickness. The main reason for this phenomenon is that rough joints induce uneven distribution of stress. The contribution of $J R C$ in this case is different from that in shear tests of single joint, but the larger JRC may also result in the higher peak shear strength.

[Fig. 13 goes here]

[Fig. 14 goes here]

[Fig. 15 goes here]

\subsubsection{Dilatancy and peak shear strength}

Fig.16 shows the variation of the shear stress and shear dilatancy of S-S joints during the double-joint shear tests. Under lower normal stress $\left(\sigma_{\mathrm{n}}=5 \% \sigma_{\mathrm{c}}\right)$, shear dilatancy increased gradually with the shear displacement. In contrast, under the higher normal stress $\left(\sigma_{\mathrm{n}}=15 \% \sigma_{\mathrm{c}}\right.$ and $\left.\sigma_{\mathrm{n}}=25 \% \sigma_{\mathrm{c}}\right)$, shear dilatancy displacement initially increased and then decreased. Its peak corresponds well with the peak shear stress and the overall strength of the combined structure is dominated by the interlayer rock.

[Fig. 16 goes here]

\subsubsection{JRC and the peak shear strength}

Fig. 17 shows the peak shear strength of the S-S joints, R-S joints and the R-R joints under normal loading of $5 \% \sigma_{\mathrm{c}}, 15 \% \sigma_{\mathrm{c}}$, or $25 \% \sigma_{\mathrm{c}}$, with an interlayer thickness of $40 \mathrm{~mm}$. The peak shear strengths of the smooth joint (JRC $=0.4)$ and the rough joints were also calculated by using Eq.1.

Under lower normal stress $\left(\sigma_{\mathrm{n}}=5 \% \sigma_{\mathrm{c}}\right)$, the interlayer rock does not fail. The peak shear strength of the 
double parallel joints was equal to that of the weaker joint. Under higher normal stress $\left(\sigma_{\mathrm{n}}=15 \% \sigma_{\mathrm{c}}\right.$ and $\sigma_{\mathrm{n}}=$ $25 \% \sigma_{\mathrm{c}}$ ), tensional cracks occur in the interlayer rock, indicating the peak shear strength is related to the interlayer rock. In this regard, the peak shear strength also increases with increasing $J R C$, but the interrelationships are more complex. Higher $J R C$ means higher shear strength for a single joint, but also means stress concentration on the joint surface, which cause tensile cracks in the interlayer rock. It is interesting to note that more evenly distributed tensile cracks were induced in the interlayer of S-S joints under higher normal stress, whose strength is even lower than that of R-R joints. Because the failure of interlayer rock has important effects on the peak shear strength of a double-joint specimen, the peak shear strength of R-R joints is higher than that of the S-S joints.

Overall, for double parallel joints, the peak shear strength increases with normal stress, but gradually tends to be lower than the strength of the weaker joint under the condition of single joint shearing. For example, the $4^{\text {th }}$ sample in Fig.14 ( interlayer thickness of 40mm, JRC values of the upper joint and the lower are 0.4 and 12.7, respectively) shows a mixed failure mode, indicated this rock sample slid along the smooth joint (but not the rough one) but also results in cracks in the interlayer rock. This phenomenon can clarify that the results of double-joint shear tests are closely related to the $J R C$ of the joints, especially that of the weaker joint.

[Fig. 17 goes here]

\subsubsection{Interlayer thickness and the peak shear strength}

Fig. 18 shows the peak shear strength of the R-S joints with $10 \mathrm{~mm}, 20 \mathrm{~mm}$, or $40 \mathrm{~mm}$ thick interlayer rock. Almost all of the peak shear strengths of the R-S joints are close to the values of smooth joints calculated using Eq.1, except for the sample of $40 \mathrm{~mm}$ thick interlayer rock was obviously smaller than the others at normal loading of $25 \% \sigma_{\mathrm{c}}$. This is because predominant tensional cracks are induced in the interlayer rock, and this phenomenon also happens to S-S joints and R-R joints when the normal loading is $25 \% \sigma_{\mathrm{c}}$ and the interlayer thickness is $40 \mathrm{~mm}$, as shown in Fig. 15.

Thus, within a certain limit, provided that the interlayer is not thick enough to remain intact during shearing, a larger thickness may lead to lower peak shear strength. Instead, when the interlayer rock becomes thinner, the peak shear strength of double-joint specimen is closer to that of the weaker joint, as shown in Fig. 18.

[Fig. 18 goes here]

In this section, the direct shear tests showed that the maximum $J R C$ along the shear direction can be used to estimate the peak shear strength. This is because the joint specimens were generated by a method similar to the Brazilian Split test and the $J R C$ values of different roughness profiles were very similar. In other cases, for 
example if the maximum $J R C$ was much bigger than the other values, this method may be not suitable to use this method to estimate the peak shear strength. In addition, to maximize the contrast, joints were broadly divided into smooth-type and rough-type.. The constant $J R C$ value of 0.4 was adopted for the smooth joints, and the classified and weighted method proposed in this study was only adopted for estimating JRC of rough joints. Further studies are required to propose a model to estimate the double-joint shear strength based on the $J R C$ values and spacing of two joints.

\section{Conclusions}

Six statistical parameters were investigated in this paper, $Z_{2}, S F, R_{\mathrm{P}^{-}}, \log \left(Z_{2}\right), \log S F$, and $\sqrt{R_{P}-1}$. These parameters are all sensitive to the sampling intervals used, therefore it is necessary to estimate the $J R C$ of a natural rock joint by considering both the first-order and the second-order asperity.

By decomposing the ordinate $\left(y_{\mathrm{i}}\right)$ of the roughness profiles, the asperities were divided into the first-order and second-order, and a classified and weighted fitting formula, $J R C=16.09 \log Z_{2}^{1 \text { st }}+12.70 \log Z_{2}^{2 \text { nd }}+33.75(S I=$ $5.0 \mathrm{~mm} \& 0.5 \mathrm{~mm})$, was proposed to estimate the $J R C$ of rock joints. In addition, shear tests on the sandstone joints indicate that the maximum $J R C$ along the shear direction is appropriate to represent the total joint surface and to estimare the .shear strength.

The classified and weighted method was adopted to estimate the $J R C$ values of double parallel joints that are subjected to double-joint shear tests. Under lower normal stress, the interlayer rock will be intact; and the JRC of the weaker joint determines the peak shear strength of a combined rock sample. Under higher normal stress, the peak shear strength of the double-joint specimen is attained when tensional cracks occur in the interlayer rock, and it is dependent on the properties of two joints. Generally, the peak shear strength also increases with the $J R C$ values of the double joints, but is dependent on the strength of interlayer rock between two joints.

If the interlayer thickness is not sufficient to remain intact during shearing, a thicker interlayer rock may lead to lower shear strength. When the interlayer rock becomes thinner, the double-joint shear strength may be closer to that of the weaker joint. Overall, shear tests on the double parallel joints are determined by a series of interrelated factors. Accurate estimation of the $J R C$ accurately is an important step, but future studies should include other key factors, such as the failure of the interlayer rock.

\section{Acknowledgements}


Funding for this work was provided by the National Science Foundation of China (Grant Nos. 51525402, 51374049, 51574060, and 51534003), the Key Project of Chinese Ministry of Education (No. 113019A), and the Fundamental Research Funds for the Central Universities of China (Grant Nos. N140105001, N140106002, and N150102002). This support is gratefully acknowledged.

\section{References}

Barton, N., (1973). Review of a new shear-strength criterion for rock joints. Eng. Geol. 7(4): 287-332.

Barton, N., Choubey, V., (1977). The shear strength of rock joints in theory and practice. Rock Mech. 10: 1-54.

Chen, S. J., Zhu W. C., Zhang M. S., Yu Q. L., (2012). Fractal description of rock joints based on digital image processing technique. Chin. J. Rock Mech. Eng. 34(11): 2087-2092 (in Chinese).

El-Soudani, S. M., (1978). Profilometric analysis of fractures. Metallography. 11(3): 247-336.

Fardin N. (2008) Influence of structural non-stationarity of surface roughness on morphological characterization and mechanical deformation of rock joints. Rock Mech. Rock. Eng. 41(2): 267-297.

Grasselli G, Wirth J, Egger P. (2002) Quantitative three-dimensional description of a rough surface and parameter evolution with shearing. Int. J. Rock Mech. Min. Sci. 39(6): 789-800.

Hoek E, Bray J. W., (1981). Rock slope engineering. London: IMM.

International Society for Rock Mechanics, 1978. Suggested methods for the quantitative description of discontinuities in rock masses. Int. J. Rock Mech. Min. Sci. 15(6): 319-368.

Jang, H. S., Kang, S. S., Jang, B. A., (2014). Determination of joint roughness coefficients using roughness parameters. Rock Mech. Rock. Eng. 47(6): 2061-2073.

Jiang, M.J., Jiang, T., Crosta, G.B., Shi, Z.M., Chen H., Zhang, N., (2015). Modeling failure of jointed rock slope with two main joint sets using a novel DEM bond contact model. Eng. Geol. 193: 79-96.

Maerz, N. H., Franklin, J. A., \& Bennett, C. P., (1990). Joint roughness measurement using shadow 
profilometry. Int. J. Rock Mech. Min. Sci. \& Geo A, 27(5): 329-343.

Myers, N. O., (1962). Characterization of surface roughness. Wear, 5(3): 182-189.

Patton F.D., (1966). Multiple model of shear failure in rock. Proceedings of the First Congress of ISRM, Lisbon. 509-513.

Re F, Scavia C. (1999) Determination of contact areas in rock joints by X-ray computer tomography. Int. J. Rock Mech. Min. Sci. 36(7): 883-890.

Sayles, R. S., Thomas, T. R., (1977). The spatial representation of surface roughness by means of the structure function: a practical alternative to correlation. Wear, 42(77): 263-276.

Tatone, B. S. A., Grasselli, G., (2010). A new 2d discontinuity roughness parameter and its correlation with JRC. Int. J. Rock Mech. Min. Sci. 47(8): 1391-1400.

Tse, R., Cruden, D. M., (1979). Estimating joint roughness coefficients. Int. J. Rock Mech. Min. Sci. \& Geo A. 16(5): 303-307.

Yang, Z. Y., Chen, J. M., Huang, T. H., (1998). Effect of joint sets on the strength and deformation of rock mass models. Int. J. Rock Mech. Min. Sci. 35(1): 75-84.

Yang, Z. Y., Lo, S. C., Di, C. C., (2001a). Reassessing the joint roughness coefficient (JRC) estimation using $\mathrm{Z}_{2}$. Rock Mech. Rock. Eng. 34(3): 243-251.

Yang, Z. Y., Di, C. C., Yen, K. C., (2001b). The effect of asperity order on the roughness of rock joints. International Int. J. Rock Mech. Min. Sci. 38(5): 745-752.

Yu, X., Vayssade, B., (1991). Joint profiles and their roughness parameters. Int. J. Rock Mech. Min. Sci. \& Geo A. 28(4): 333-336. 


\section{List of tables}

Table 1 Sum of squared error (SSE) of the fitting formulas

Table 2 Physical and mechanical properties of sandstone specimens

Table $3 J R C$ values of the 5 sandstone specimens used for the direct shear tests calculated using Eq. 11 or Eq. 5

Table 4 Experimental peak shear strength of the sandstone specimens and those estimated by Eq.1

Table $5 J R C$ of the sandstone specimens calculated by Eq. 1 or by Eq. 11 and Eq. 5

Table 6 Maximum $J R C$ values calculated by Eq.11 for different profile spacings ( $S I=5.0 \& 0.5 \mathrm{~mm}$ ) 
Table 1

Sum of squared error (SSE) of the fitting formulas

\begin{tabular}{|c|c|c|c|c|c|c|c|c|c|}
\hline \multirow{2}{*}{$\begin{array}{l}\text { Statistical } \\
\text { parameters }\end{array}$} & \multicolumn{9}{|c|}{ Sampling interval/mm } \\
\hline & 0.25 & 0.5 & 1.0 & 2.0 & 5.0 & 10.0 & $2.5 \& 0.25$ & $5.0 \& 0.5$ & $10.0 \& 1.0$ \\
\hline$Z_{2}$ & 104.58 & 47.81 & 22.68 & 10.69 & 16.30 & 30.84 & 6.04 & 12.36 & 12.12 \\
\hline$S F$ & 120.48 & 75.41 & 53.49 & 44.16 & 45.88 & 59.22 & 25.28 & 26.77 & 40.26 \\
\hline$R_{\mathrm{P}^{-}}-1$ & 113.96 & 67.09 & 47.89 & 36.22 & 39.85 & 63.47 & 22.91 & 39.11 & 39.88 \\
\hline $\log \left(Z_{2}\right)$ & 93.06 & 32.63 & 13.02 & 9.69 & 13.26 & 22.37 & 5.66 & 3.73 & 7.45 \\
\hline $\log (S F)$ & 92.97 & 32.63 & 13.04 & 10.33 & 13.26 & 23.63 & 5.66 & 8.02 & 6.70 \\
\hline$\sqrt{R_{P}-1}$ & 100.05 & 39.95 & 21.04 & 8.43 & 13.28 & 30.83 & 5.04 & 11.92 & 11.61 \\
\hline
\end{tabular}


Table 2

Physical and mechanical properties of sandstone specimens

\begin{tabular}{ccccccc}
\hline $\begin{array}{c}\text { Elastic modulus / } \\
\text { GPa }\end{array}$ & $\begin{array}{c}\text { Poisson's } \\
\text { ratio }\end{array}$ & $\begin{array}{c}\text { Uniaxial } \\
\text { compressive } \\
\text { strength } / \\
\mathrm{MPa}\end{array}$ & Cohesion / MPa & $\begin{array}{c}\text { Tensile strength } \\
/ \mathrm{MPa}\end{array}$ & $\begin{array}{c}\text { Internal } \\
\text { friction } \\
\text { angle }^{\circ}\end{array}$ & $\begin{array}{c}\text { Basic friction } \\
\text { angle } /^{\circ}\end{array}$ \\
\hline 8.4 & 0.29 & 32.2 & 5.92 & 2.29 & 27.4 & 34.5 \\
\hline
\end{tabular}




\section{Table 3}

$J R C$ values of the 5 sandstone specimens used for the direct shear tests calculated using Eq. 11 or Eq. 5

\begin{tabular}{|c|c|c|c|c|c|c|c|c|c|c|}
\hline \multirow{2}{*}{$\begin{array}{c}\text { Serial } \\
\text { number }\end{array}$} & \multicolumn{2}{|c|}{ Sample No.1 } & \multicolumn{2}{|c|}{ Sample No.2 } & \multicolumn{2}{|c|}{ Sample No.3 } & \multicolumn{2}{|c|}{ Sample No.4 } & \multicolumn{2}{|c|}{ Sample No.5 } \\
\hline & $\begin{array}{c}\text { Eq. } 11, \\
S I=5.0 \& 0.5 \mathrm{~mm}\end{array}$ & $\begin{array}{c}\text { Eq.5, } \\
S I=5.0 \mathrm{~mm}\end{array}$ & $\begin{array}{c}\text { Eq. } 11, \\
S I=5.0 \& 0.5 \mathrm{~mm}\end{array}$ & $\begin{array}{c}\text { Eq. } 5, \\
S I=5.0 \mathrm{~mm}\end{array}$ & $\begin{array}{c}\text { Eq. } 11, \\
S I=5.0 \& 0.5 \mathrm{~mm}\end{array}$ & $\begin{array}{c}\text { Eq.5, } \\
S I=5.0 \mathrm{~mm}\end{array}$ & $\begin{array}{c}\text { Eq. } 11, \\
S I=5.0 \& 0.5 \mathrm{~mm}\end{array}$ & $\begin{array}{c}\text { Eq.5, } \\
S I=5.0 \mathrm{~mm}\end{array}$ & $\begin{array}{c}\text { Eq. } 11, \\
S I=5.0 \& 0.5 \mathrm{~mm}\end{array}$ & $\begin{array}{c}\text { Eq. } 5, \\
S I=5.0 \mathrm{~mm}\end{array}$ \\
\hline 1 & 12.35 & 13.46 & 8.79 & 10.53 & 13.77 & 14.84 & 15.51 & 16.63 & 15.38 & 16.72 \\
\hline 2 & 13.42 & 14.46 & 9.73 & 12.18 & 14.40 & 15.39 & 14.08 & 15.60 & 11.70 & 14.09 \\
\hline 3 & 15.15 & 16.01 & 10.71 & 13.01 & 15.40 & 16.24 & 8.79 & 11.69 & 11.91 & 13.27 \\
\hline 4 & 13.70 & 15.02 & 9.79 & 12.26 & 14.89 & 15.73 & 9.32 & 11.91 & 12.88 & 14.28 \\
\hline 5 & 14.53 & 16.03 & 8.67 & 11.83 & 14.76 & 15.93 & 11.38 & 13.29 & 12.23 & 13.11 \\
\hline 6 & 15.44 & 16.34 & 13.50 & 14.76 & 15.41 & 16.24 & 11.96 & 13.45 & 11.88 & 13.59 \\
\hline 7 & 15.52 & 16.45 & 14.42 & 15.50 & 14.97 & 16.20 & 13.63 & 14.65 & 10.82 & 13.07 \\
\hline 8 & 13.36 & 14.82 & 13.24 & 14.11 & 11.81 & 14.18 & 12.62 & 14.22 & 8.86 & 10.90 \\
\hline 9 & 14.60 & 15.74 & 9.47 & 11.56 & 14.38 & 15.09 & 12.85 & 14.75 & 9.11 & 11.31 \\
\hline 10 & 13.65 & 14.74 & 8.70 & 11.93 & 14.01 & 16.44 & 12.49 & 14.14 & 10.28 & 12.76 \\
\hline Average & 14.17 & 15.31 & 10.70 & 12.77 & 14.38 & 15.63 & 12.26 & 14.03 & 11.50 & 13.31 \\
\hline Maximum & 15.52 & 16.45 & 14.42 & 15.50 & 15.41 & 16.44 & 15.51 & 16.63 & 15.38 & 16.72 \\
\hline Minimum & 12.35 & 13.46 & 8.67 & 10.53 & 11.81 & 14.18 & 8.79 & 11.69 & 8.86 & 10.90 \\
\hline
\end{tabular}




\section{Table 4}

Experimental peak shear strength of the sandstone specimens and those estimated by Eq.1

\begin{tabular}{|c|c|c|c|c|c|c|c|c|c|c|c|c|c|c|}
\hline \multirow{3}{*}{$\begin{array}{c}\text { Serial } \\
\text { number }\end{array}$} & \multirow{3}{*}{$\begin{array}{l}\text { Normal } \\
\text { pressure }\end{array}$} & \multirow{3}{*}{$\begin{array}{c}\text { Experimental } \\
\text { peak shear } \\
\text { strength } \\
/ \mathrm{MPa}\end{array}$} & \multicolumn{12}{|c|}{ Estimated peak shear strength by Eq. 1 /MPa } \\
\hline & & & \multicolumn{6}{|c|}{$J R C$ calculated by Eq. $11, S I=5.0 \& 0.5 \mathrm{~mm}$} & \multicolumn{5}{|c|}{$J R C$ calculated by Eq. $5, S I=0.5 \mathrm{~mm}$} & \multirow[b]{2}{*}{$\begin{array}{c}\text { Estimation } \\
\text { error }\end{array}$} \\
\hline & & & $\begin{array}{l}\text { Ave } \\
J R C\end{array}$ & $\begin{array}{c}\text { Estimation } \\
\text { error }\end{array}$ & $\begin{array}{l}\text { Max } \\
J R C\end{array}$ & $\begin{array}{c}\text { Estimation } \\
\text { error }\end{array}$ & $\begin{array}{l}\text { Min } \\
J R C\end{array}$ & $\begin{array}{l}\text { Estimation } \\
\text { error }\end{array}$ & $\begin{array}{l}\text { Ave } \\
J R C\end{array}$ & $\begin{array}{c}\text { Estimation } \\
\text { error }\end{array}$ & $\begin{array}{l}\text { Max } \\
J R C\end{array}$ & $\begin{array}{c}\text { Estimation } \\
\text { error }\end{array}$ & $\begin{array}{l}\text { Min } \\
J R C\end{array}$ & \\
\hline Sample No.1 & $5 \% \sigma_{\mathrm{c}}$ & 2.191 & 2.132 & $-2.71 \%$ & 2.273 & $3.75 \%$ & 1.958 & $-10.64 \%$ & 2.250 & $2.70 \%$ & 2.378 & $8.55 \%$ & 2.062 & $-5.89 \%$ \\
\hline Sample No.2 & $10 \% \sigma_{\mathrm{c}}$ & 3.838 & 3.243 & $-15.51 \%$ & 3.694 & $-3.75 \%$ & 3.021 & $-21.30 \%$ & 3.486 & $-9.18 \%$ & 3.837 & $-0.02 \%$ & 3.223 & $-16.03 \%$ \\
\hline Sample No.3 & $15 \% \sigma_{\mathrm{c}}$ & 5.628 & 5.063 & $-10.04 \%$ & 5.215 & $-7.34 \%$ & 4.702 & $-16.46 \%$ & 5.248 & $-6.75 \%$ & 5.372 & $-4.55 \%$ & 5.034 & $-10.55 \%$ \\
\hline Sample No.4 & $20 \% \sigma_{\mathrm{c}}$ & 6.207 & 6.020 & $-3.01 \%$ & 6.516 & $4.98 \%$ & 5.528 & $-10.94 \%$ & 6.287 & $1.28 \%$ & 6.698 & $7.91 \%$ & 5.936 & $-4.36 \%$ \\
\hline Sample No.5 & $30 \% \sigma_{\mathrm{c}}$ & 9.014 & 8.255 & $-8.42 \%$ & 8.864 & $-1.66 \%$ & 7.860 & $-12.80 \%$ & 8.534 & $-5.32 \%$ & 9.086 & $0.79 \%$ & 8.163 & $-9.44 \%$ \\
\hline SSE & - & - & - & 428.74\% & - & $109.58 \%$ & - & $1121.28 \% \mathrm{mon}$ & - & $167.18 \%$ & - & $156.85 \%$ & - & $511.09^{1 / m o w}$ \\
\hline
\end{tabular}




\section{Table 5}

$J R C$ of the sandstone specimens calculated by Eq.1 or by Eq.11 and Eq.5

\begin{tabular}{|c|c|c|c|c|c|c|c|c|c|c|c|c|c|c|}
\hline \multirow{3}{*}{$\begin{array}{c}\text { Serial } \\
\text { number }\end{array}$} & \multirow{3}{*}{$\begin{array}{l}\text { Normal } \\
\text { pressure }\end{array}$} & \multirow{3}{*}{$\begin{array}{l}J R C \text { back-calculated } \\
\text { by experiments, Eq.1 }\end{array}$} & \multicolumn{12}{|c|}{$J R C$ calculated by estimation formulas } \\
\hline & & & \multicolumn{6}{|c|}{$J R C$ calculated by Eq. $11, S I=5.0 \& 0.5 \mathrm{~mm}$} & \multicolumn{5}{|c|}{$J R C$ calculated by Eq. $5, S I=0.5 \mathrm{~mm}$} & \multirow[b]{2}{*}{$\begin{array}{c}\text { Estimated } \\
\text { error }\end{array}$} \\
\hline & & & $\begin{array}{l}\text { Ave. } \\
J R C\end{array}$ & $\begin{array}{l}\text { Estimated } \\
\text { error }\end{array}$ & $\begin{array}{l}\text { Max. } \\
J R C\end{array}$ & $\begin{array}{c}\text { Estimated } \\
\text { error }\end{array}$ & $\begin{array}{l}\text { Min. } \\
\text { JRC }\end{array}$ & $\begin{array}{l}\text { Estimated } \\
\text { error }\end{array}$ & $\begin{array}{l}\text { Ave. } \\
J R C\end{array}$ & $\begin{array}{l}\text { Estimated } \\
\text { error }\end{array}$ & $\begin{array}{l}\text { Max. } \\
J R C\end{array}$ & $\begin{array}{l}\text { Estimated } \\
\text { error }\end{array}$ & $\begin{array}{l}\text { Min. } \\
\text { JRC }\end{array}$ & \\
\hline Sample No.1 & $5 \% \sigma_{\mathrm{c}}$ & 14.75 & 14.17 & $-3.92 \%$ & 15.52 & $5.22 \%$ & 12.35 & $-16.27 \%$ & 15.31 & $3.78 \%$ & 16.45 & $11.53 \%$ & 13.46 & $-8.72 \%$ \\
\hline Sample No.2 & $10 \% \sigma_{\mathrm{c}}$ & 15.50 & 10.70 & $-30.98 \%$ & 14.42 & $-6.98 \%$ & 8.67 & $-44.08 \%$ & 12.77 & $-17.65 \%$ & 15.50 & $-0.04 \%$ & 10.53 & $-32.11 \%$ \\
\hline Sample No.3 & $15 \% \sigma_{\mathrm{c}}$ & 18.04 & 14.38 & $-20.29 \%$ & 15.41 & $-14.59 \%$ & 11.81 & $-34.54 \%$ & 15.63 & $-13.38 \%$ & 16.44 & $-8.89 \%$ & 14.18 & $-21.38 \%$ \\
\hline Sample No.4 & $20 \% \sigma_{\mathrm{c}}$ & 13.51 & 12.26 & $-9.25 \%$ & 15.51 & $14.75 \%$ & 8.79 & $-34.98 \%$ & 14.03 & $3.86 \%$ & 16.63 & $23.07 \%$ & 11.69 & $-13.51 \%$ \\
\hline Sample No.5 & $30 \% \sigma_{\mathrm{c}}$ & 16.29 & 11.50 & $-29.38 \%$ & 15.38 & $-5.62 \%$ & 8.86 & $-45.60 \%$ & 13.31 & $-18.31 \%$ & 16.72 & $2.66 \%$ & 10.90 & $-33.11 \%$ \\
\hline SSE & - & - & - & 2335.66 wo & - & 537.89 \% & - & 6703.43 \% & - & $854.72 \%$ & - & 751.50 你 & - & 2843.02 \% \\
\hline
\end{tabular}


Table 6

Maximum $J R C$ values calculated by Eq.11 for different profile spacings $(S I=5.0 \& 0.5 \mathrm{~mm})$

\begin{tabular}{|c|c|c|c|c|c|c|c|c|c|c|}
\hline \multirow{2}{*}{$\begin{array}{l}\text { Profile } \\
\text { spacing }\end{array}$} & \multicolumn{2}{|c|}{ Sample No.1 } & \multicolumn{2}{|c|}{ Sample No. 2} & \multicolumn{2}{|c|}{ Sample No.3 } & \multicolumn{2}{|c|}{ Sample No.4 } & \multicolumn{2}{|c|}{ Sample No.5 } \\
\hline & $\begin{array}{l}\text { Max } \\
J R C\end{array}$ & $\begin{array}{l}\text { Relative } \\
\text { tolerance }\end{array}$ & $\begin{array}{l}\text { Max } \\
J R C\end{array}$ & $\begin{array}{l}\text { Relative } \\
\text { tolerance }\end{array}$ & $\begin{array}{l}\text { Max } \\
J R C\end{array}$ & $\begin{array}{l}\text { Relative } \\
\text { tolerance }\end{array}$ & $\begin{array}{l}\text { Max } \\
J R C\end{array}$ & $\begin{array}{l}\text { Relative } \\
\text { tolerance }\end{array}$ & $\begin{array}{l}\text { Max } \\
J R C\end{array}$ & $\begin{array}{l}\text { Relative } \\
\text { tolerance }\end{array}$ \\
\hline $18 \mathrm{~mm}$ & 15.44 & - & 13.50 & - & 15.40 & - & 14.08 & - & 12.88 & - \\
\hline $9 \mathrm{~mm}$ & 15.52 & $0.52 \%$ & 14.42 & $6.38 \%$ & 15.41 & $0.06 \%$ & 15.51 & $9.22 \%$ & 15.38 & $16.25 \%$ \\
\hline $4.5 \mathrm{~mm}$ & 15.56 & $0.26 \%$ & 15.10 & $4.50 \%$ & 15.79 & $2.41 \%$ & 15.51 & $0 \%$ & 15.38 & $0 \%$ \\
\hline
\end{tabular}




\section{List of figures}

Fig. 1 Correlation between the statistical parameters and sampling intervals

Fig. $2 J R C$ values from Barton and Choubey (1977) and the ones estimated by using our formula (Eq.11)

Fig. 3 The decomposed $10^{\text {th }}$ typical roughness profile for (a) $P_{0}(0.5)$, (b) $P_{1}(5.0)$, and (c) $P_{2}(0.5)$

Fig. 4 Statistical parameters of the decomposed ten typical roughness profiles

Fig. 5 Three-dimensional fitting graphics of $J R C$ by using the classified and weighted statistical parameters

Fig. 6 Joint surface of sandstone specimen for the shear tests

Fig. 7 Retrieval of the digital image of the rock joint surface by the 3D scanning system (a) the Comet L3D 3D scanning system, (b) the 3D image of the rock joint

Fig. 8 Shear stress- displacement curves of 5 sandstone specimens

Fig. 9 The roughness profile of the main sheared area showed maximum $J R C$ value

Fig. 10 Experimental configuration of the double-joint shear tests

Fig. 11 Experimental design of sandstone specimens containing double parallel joints

Fig. 12 The shear stress - shear displacement curves of double-joint shear tests (a) normal stress $\sigma_{\mathrm{n}}$ $=5 \% \sigma_{\mathrm{c}},(\mathrm{b})$ normal stress $\sigma_{\mathrm{n}}=15 \% \sigma_{\mathrm{c}},(\mathrm{c})$ normal stress $\sigma_{\mathrm{n}}=25 \% \sigma_{\mathrm{c}}$

Fig. 13 Shear failure processes of the sandstone samples containing double parallel joints under normal stress of $\sigma_{\mathrm{n}}=5 \% \sigma_{\mathrm{c}}$

Fig. 14 Shear failure processes of the sandstone samples containing double parallel joints under normal stress of $\sigma_{\mathrm{n}}=15 \% \sigma_{\mathrm{c}}$

Fig. 15 Shear failure processes of the sandstone samples containing double parallel joints under normal stress of $\sigma_{\mathrm{n}}=25 \% \sigma_{\mathrm{c}}$

Fig. 16 The variation of shear stress and shear dilatancy during the double-joint shear tests

Fig. 17 The influence of $J R C$ on the peak shear strength

Fig. 18 The influence of interlayer thickness on the peak shear strength 


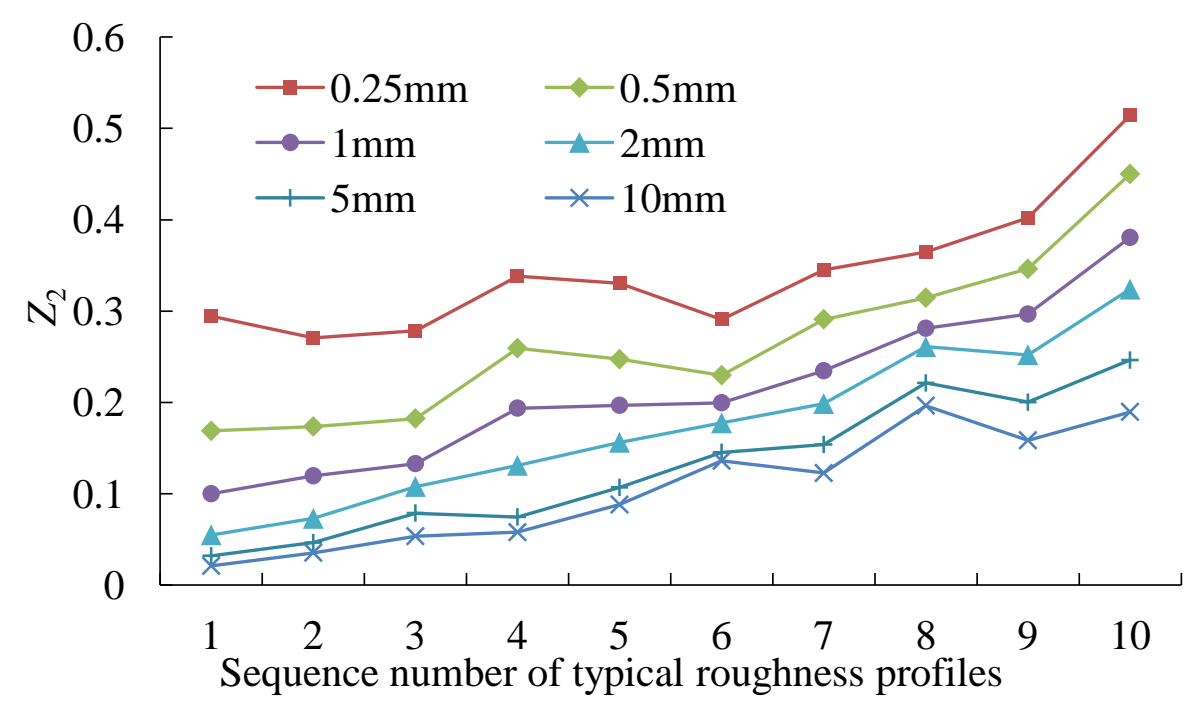

(a) $Z_{2}$

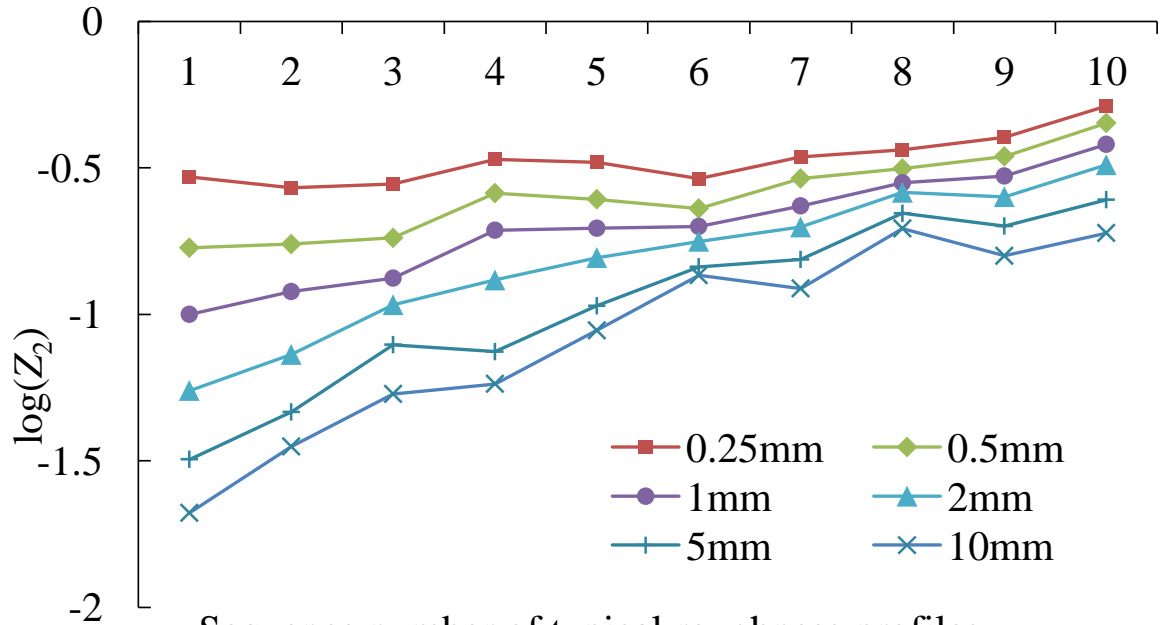

Sequence number of typical roughness profiles

(b) $\log \left(Z_{2}\right)$

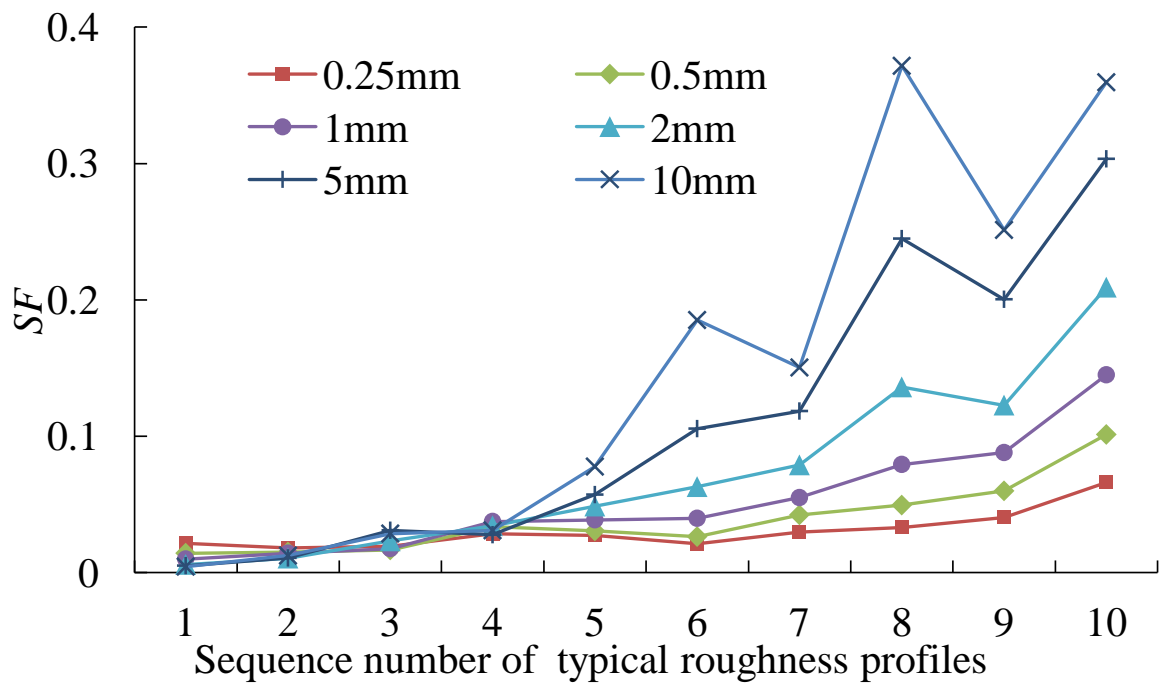

(c) $S F$ 


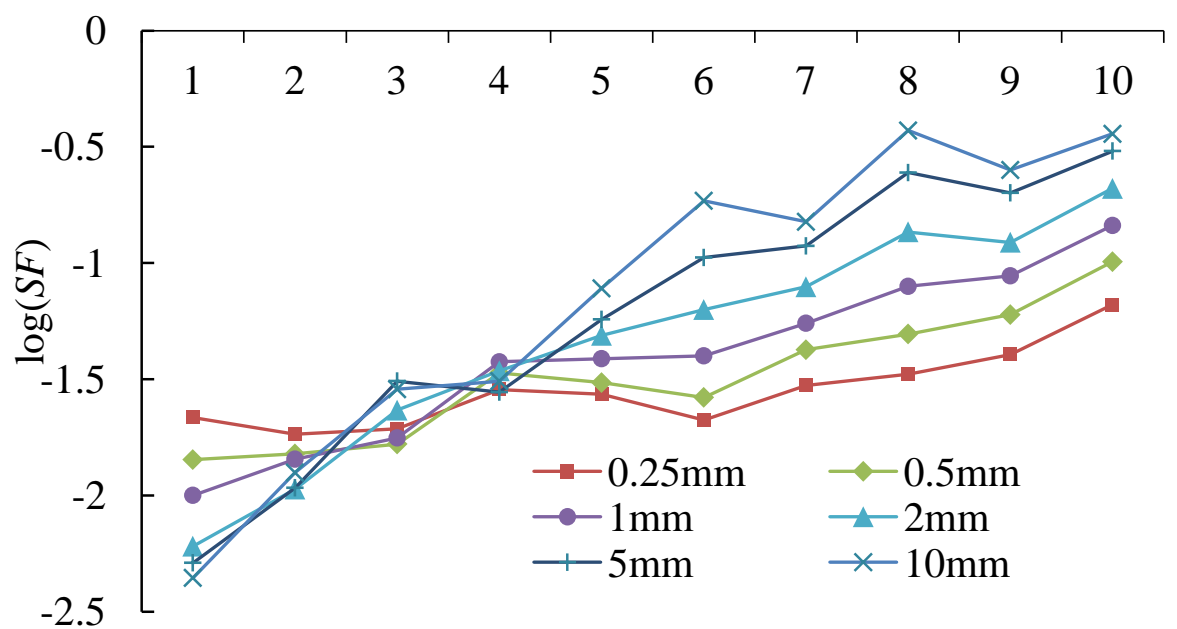

Sequence number of typical roughness profiles

(d) $\log (S F)$

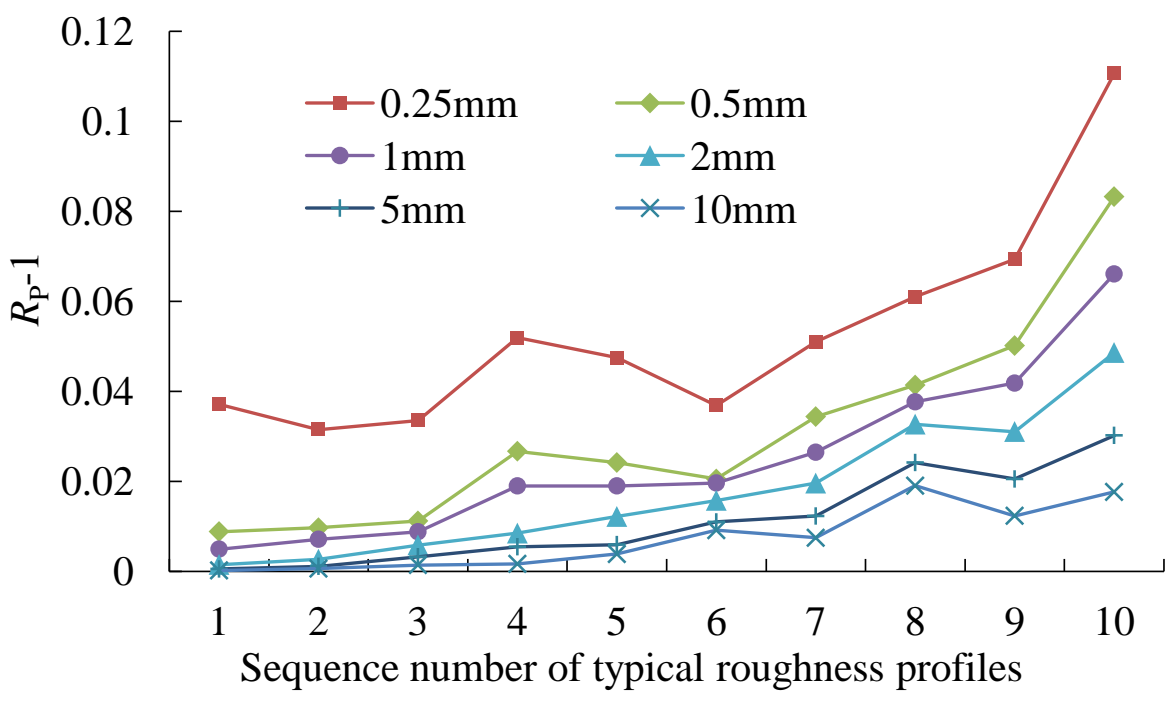

(e) $R_{\mathrm{P}}-1$

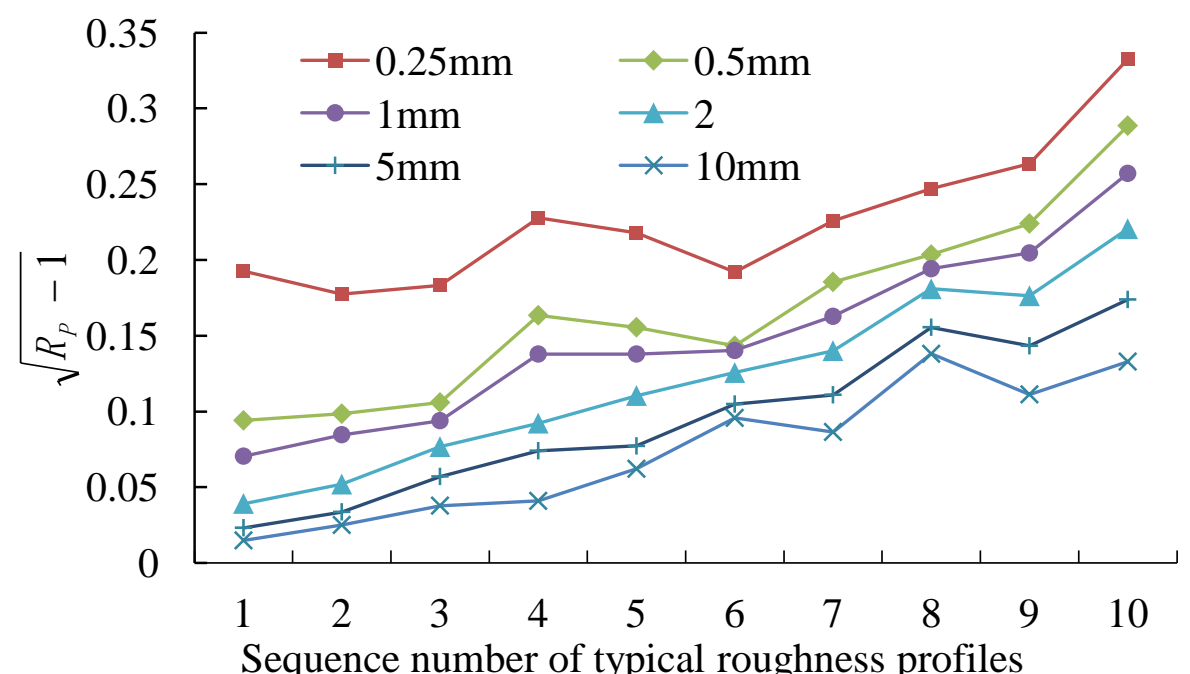

(f) $\sqrt{R_{\mathrm{P}}-1}$

Fig. 1 Correlation between the statistical parameters and sampling intervals 


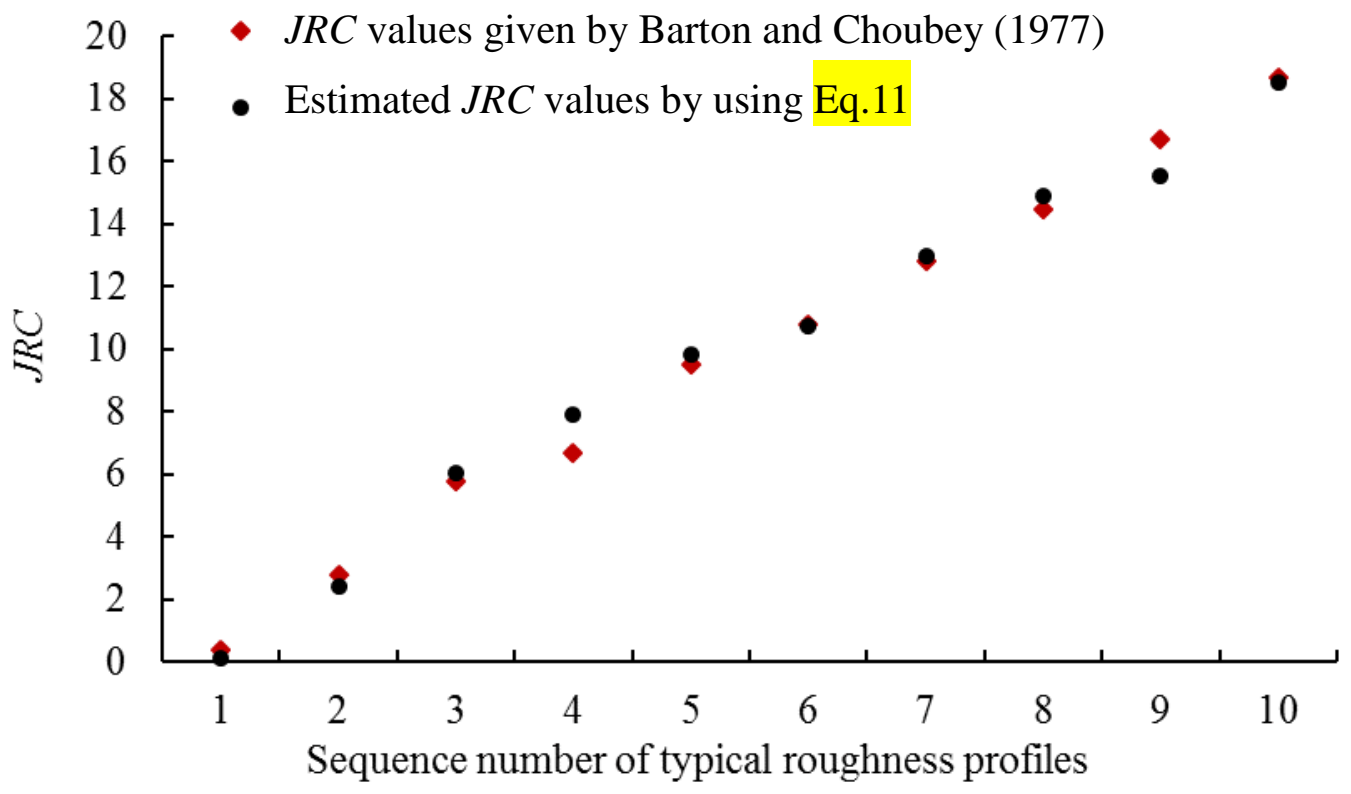

Fig.2 JRC values given by Barton and Choubey (1977) and the estimated ones by using our formula (Eq.11) 


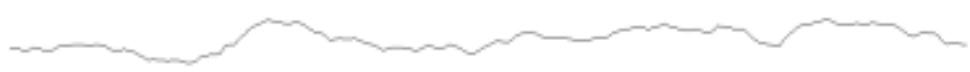

(a)

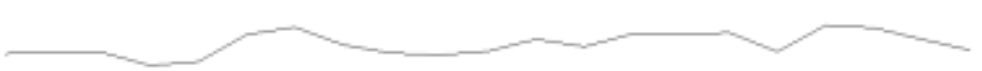

(b)

(c)

Fig.3 The decomposed $10^{\text {th }}$ typical roughness profile for (a) $P_{0}(0.5)$, (b) $P_{1}(5.0)$, and (c) $P_{2}(0.5)$ 


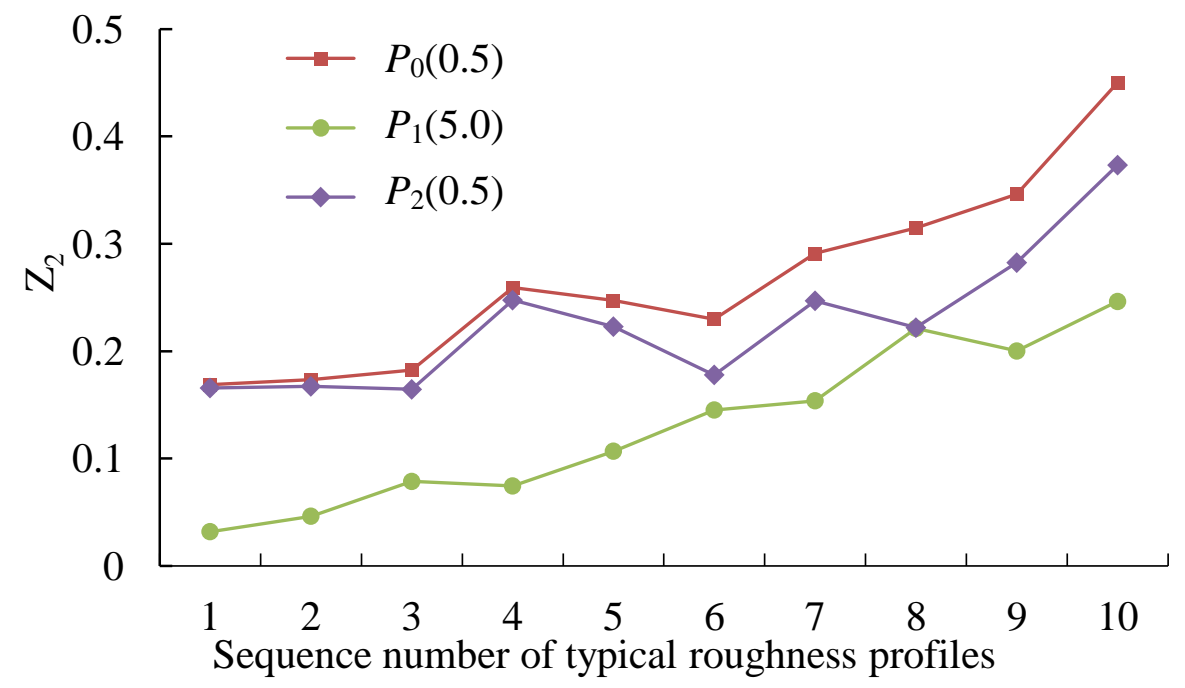

(a) $Z_{2}$

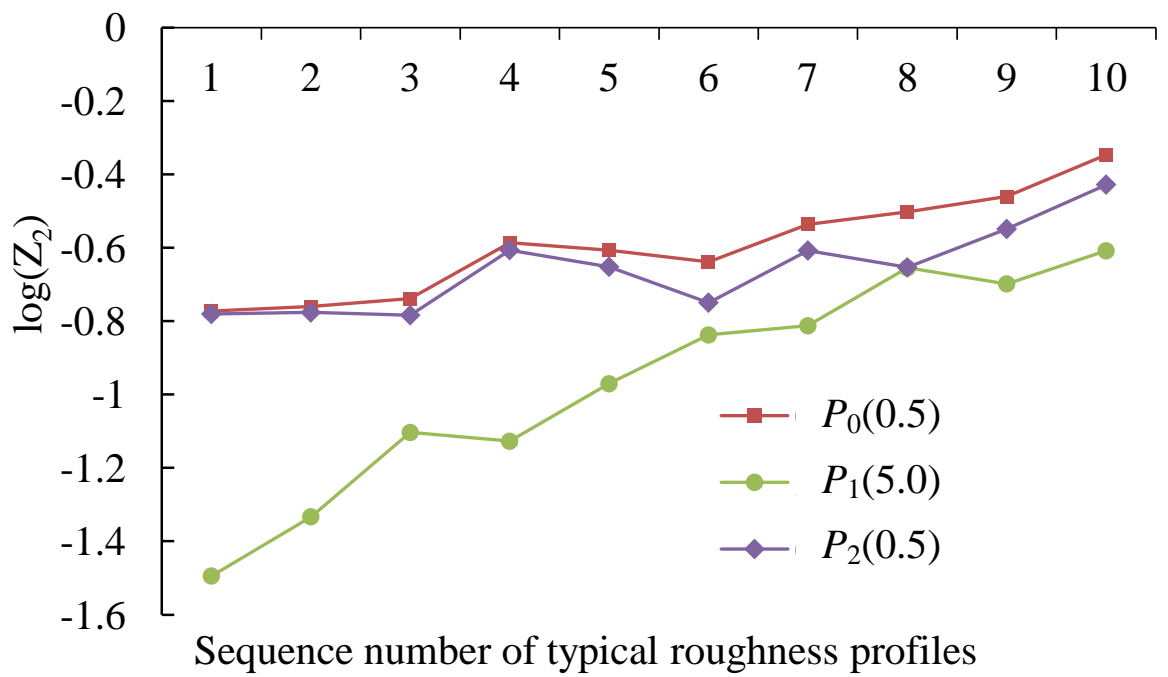

(b) $\log \left(Z_{2}\right)$

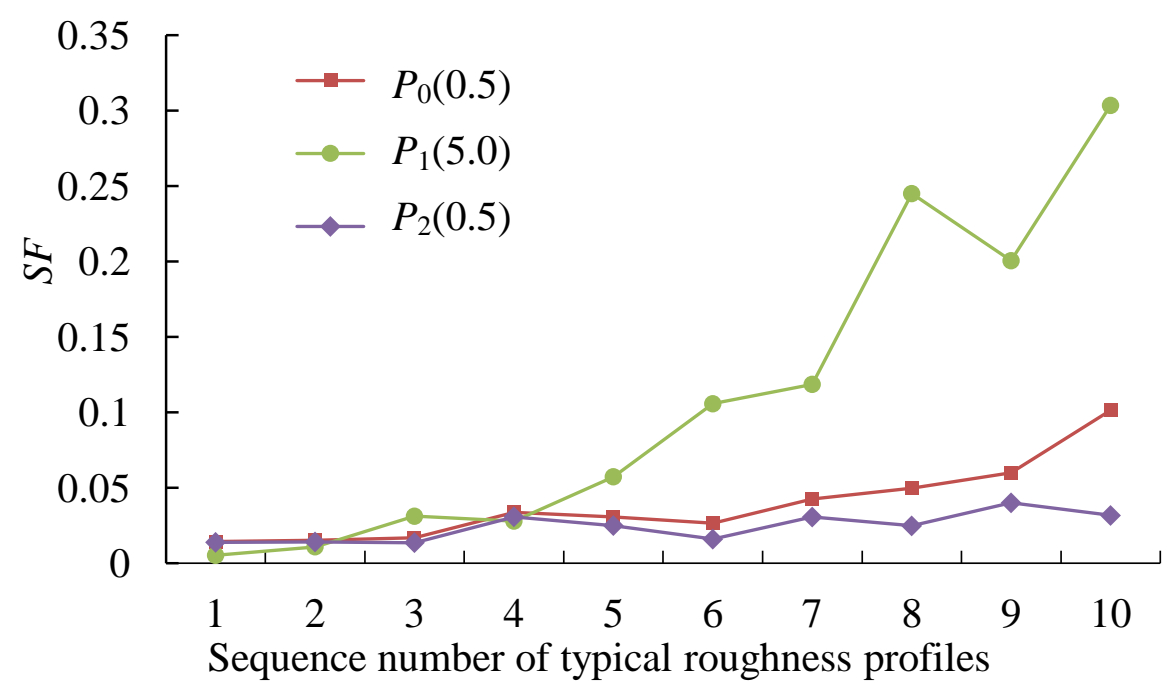

(c) $S F$ 


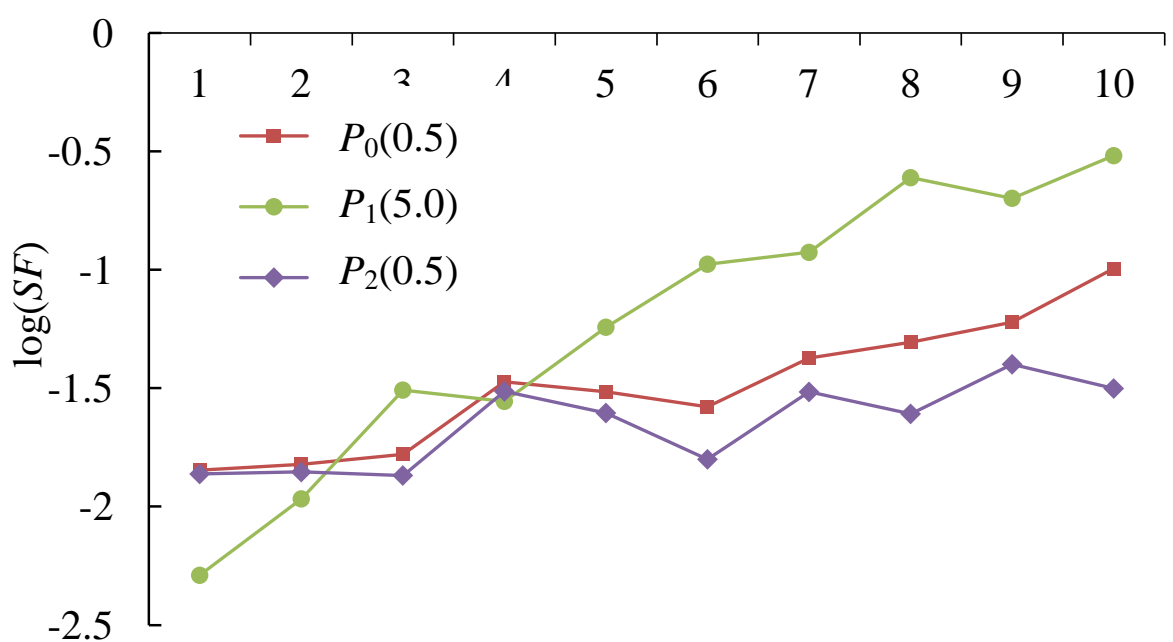

Sequence number of typical roughness profiles

(d) $\log (S F)$

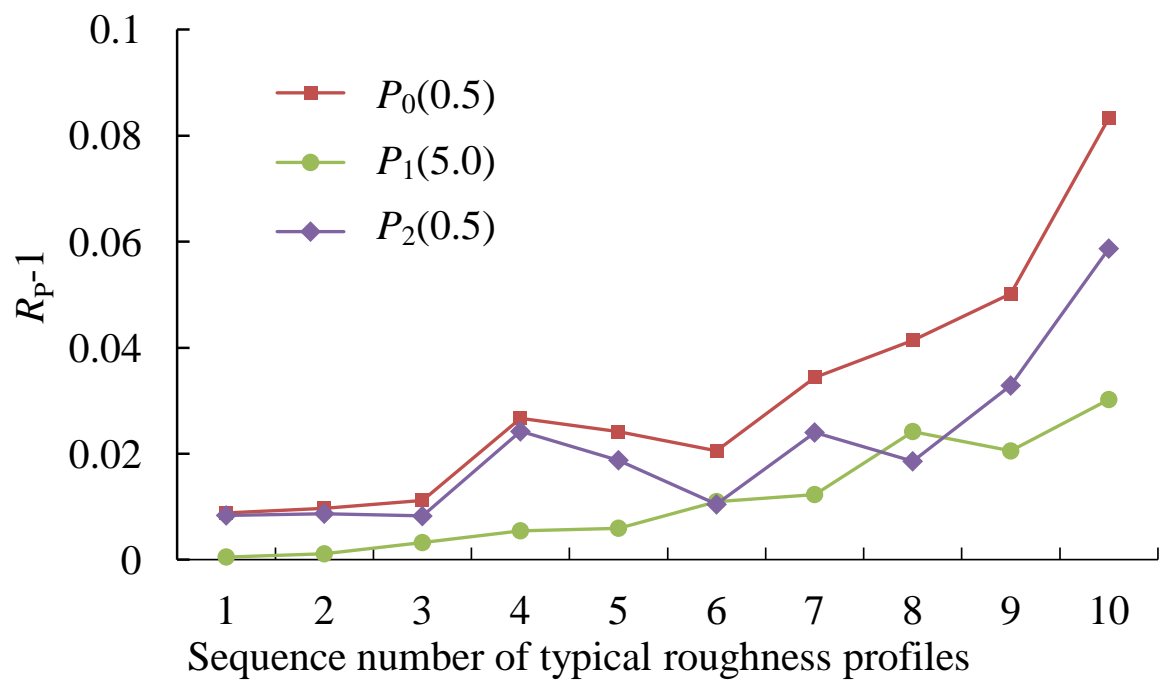

(e) $R_{\mathrm{P}^{-}} 1$

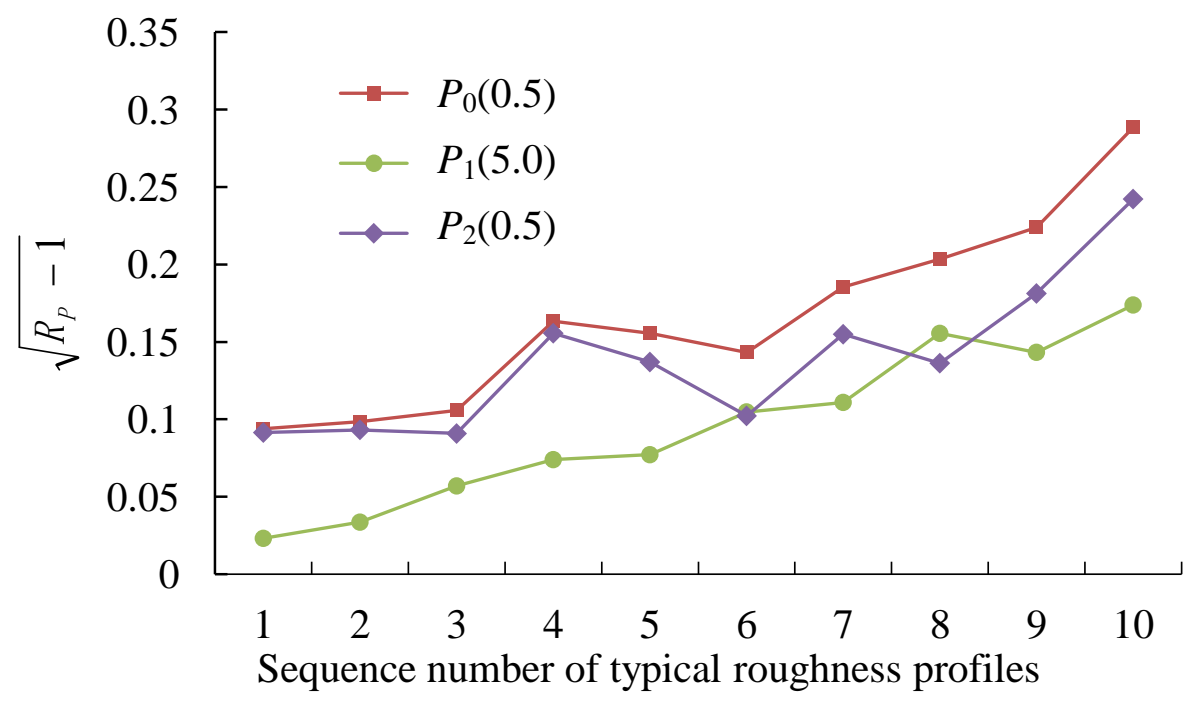

(f) $\sqrt{R_{\mathrm{P}}-1}$

Fig.4 JRC values from Barton and Choubey (1977) and the ones estimated by using our formula 
(Eq.11) 


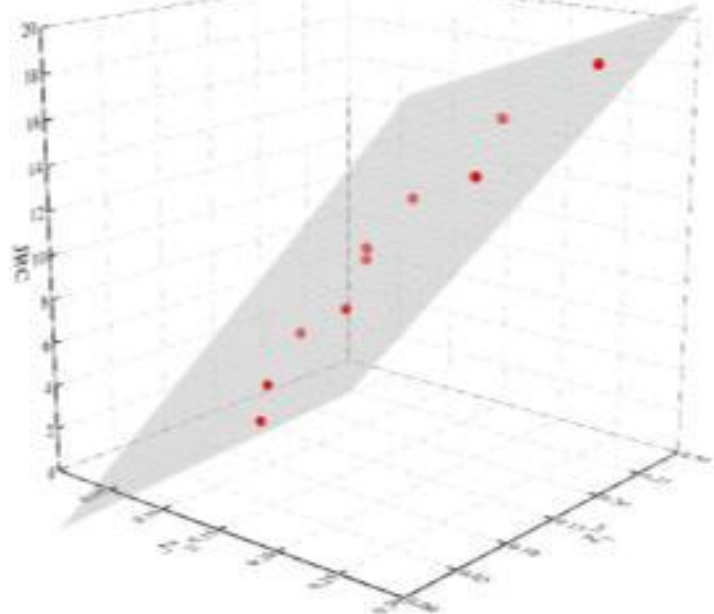

(a) Eq.(8): $J R C=75.11 Z_{2}^{1 \text { st }}+3.33 Z_{2}^{2 \text { nd }}-2.79$

$(S I=2.5 \mathrm{~mm} \& 0.25 \mathrm{~mm})$

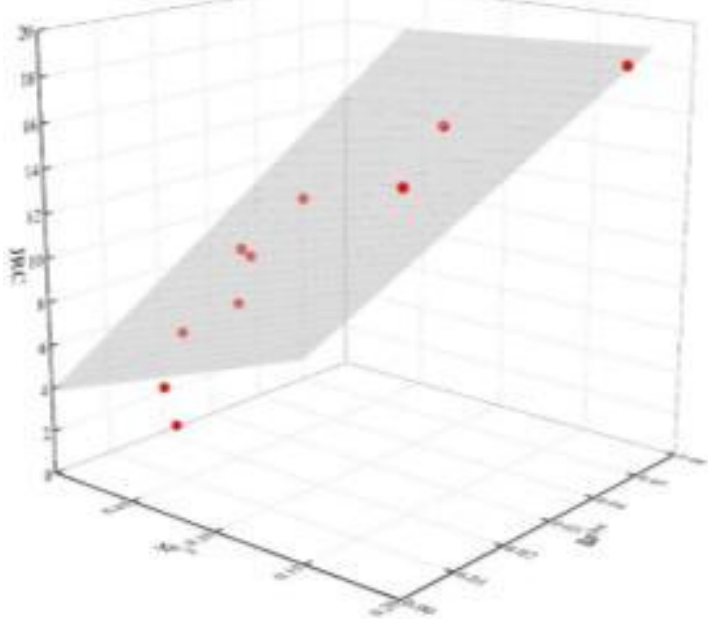

(c) Eq.(9): $J R C=91.73 S F^{1 \mathrm{st}}-57.13 S F^{2 \mathrm{nd}}+3.89$

$(S I=2.5 \mathrm{~mm} \& 0.25 \mathrm{~mm})$

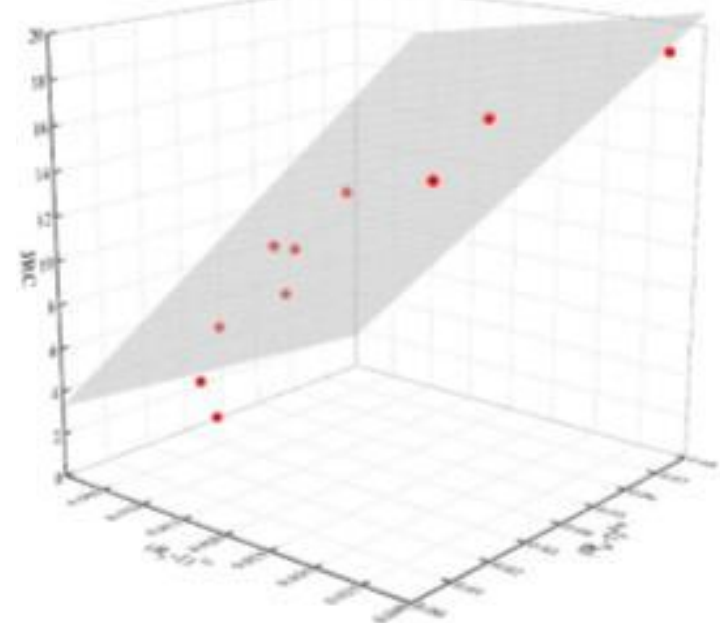

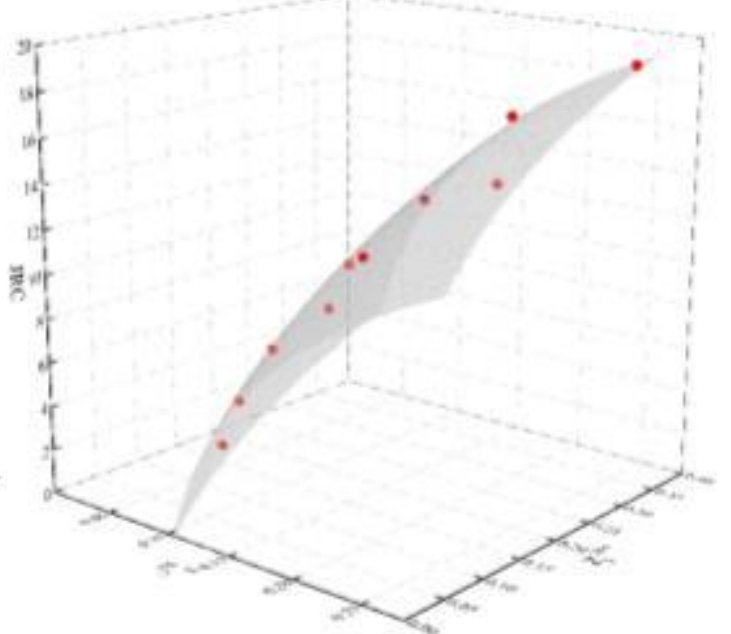

(b) Eq.(11): $J R C=16.09 \log Z_{2}^{1 \text { st }}+12.70 \log Z_{2}^{2 \text { nd }}+33.75$ $(S I=5.0 \mathrm{~mm} \& 0.5 \mathrm{~mm})$

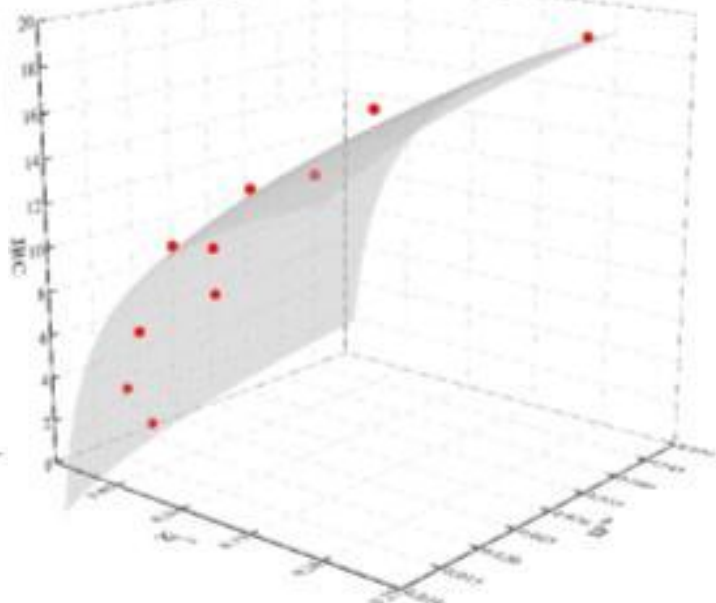

(d) Eq.(12): $J R C=11.32 \log S F^{1 \mathrm{st}}+5.79 \log S F^{2 \mathrm{nd}}+34.17$ $(S I=2.5 \mathrm{~mm} \& 0.25 \mathrm{~mm})$

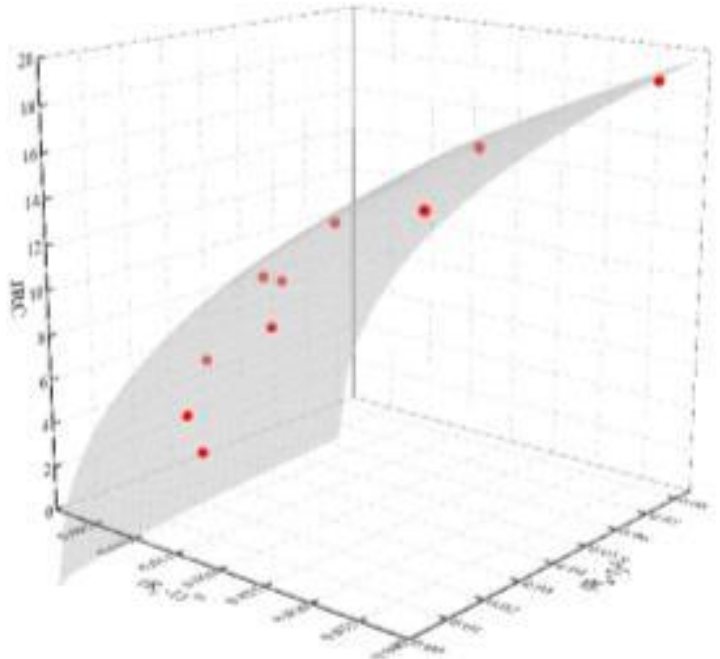

(e) Eq.(10): $J R C=472.16\left(R_{\mathrm{P}}-1\right)^{1 \mathrm{st}}-20.42\left(R_{\mathrm{P}}-1\right)^{2 \mathrm{nd}}+3.32$ (f) Eq.(13): $J R C=108.12{\sqrt{\mathrm{R}_{\mathrm{P}}-1}}^{1 \mathrm{st}}+6.31{\sqrt{R_{P}-1}}^{2 \mathrm{nd}}-3.66$ $(S I=2.5 \mathrm{~mm} \& 0.25 \mathrm{~mm})$ $(S I=2.5 \mathrm{~mm} \& 0.25 \mathrm{~mm})$

Fig.5 Three-dimensional fitting surface of $J R C$ by using the classified and weighted statistical parameters 


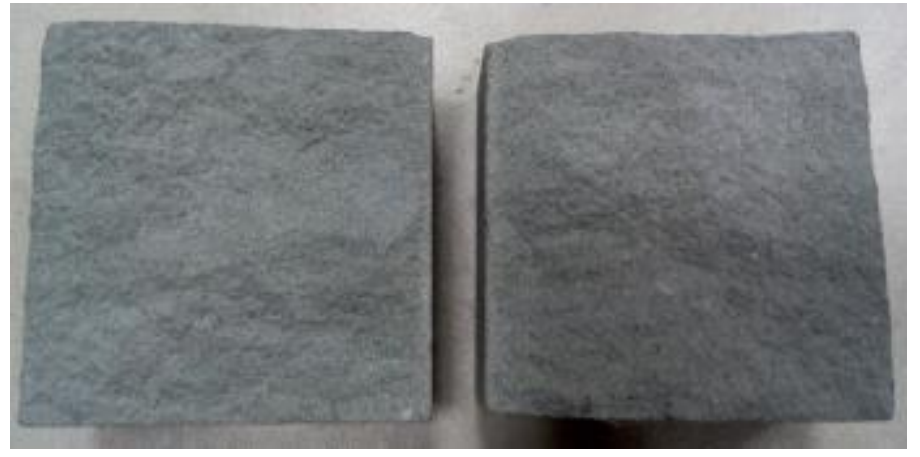

Fig.6 Joint surface of sandstone specimen for the shear tests 


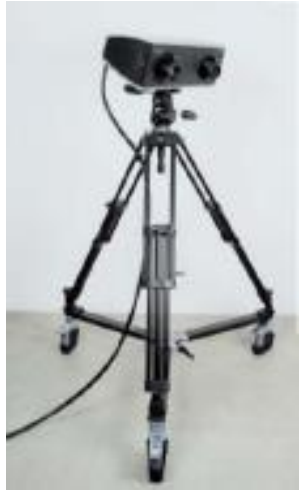

(a)

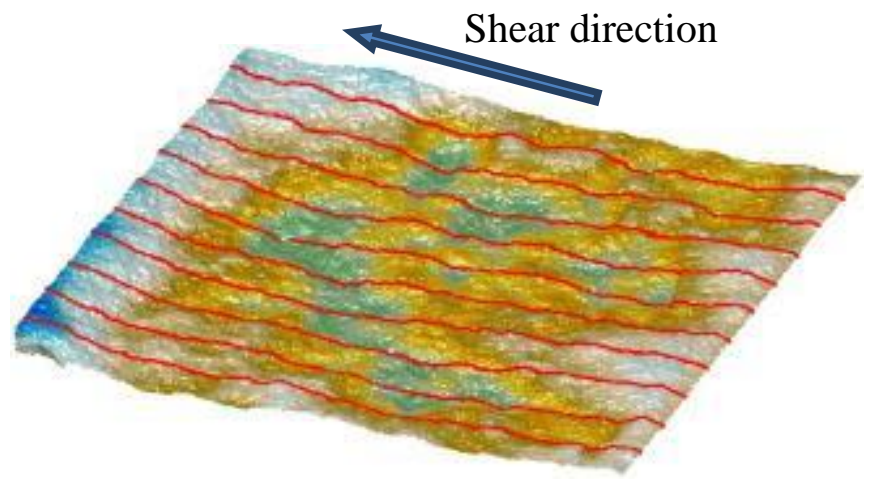

(b)

Fig.7 Retrieval of the digital image of the rock joint surface by using the 3D scanning system (a) the Comet L3D 3D scanning system, (b) the 3D image of the rock joint 


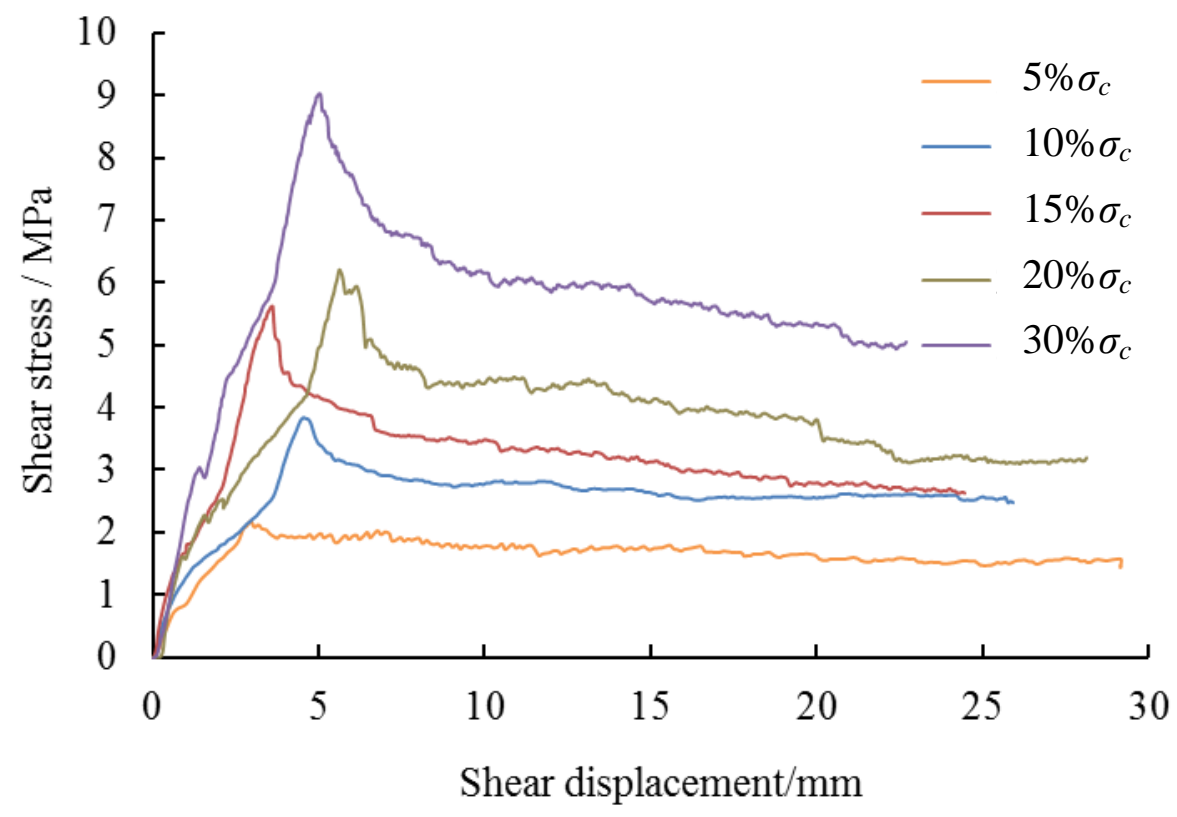

Fig.8 Shear stress- displacement curves of 5 sandstone specimens 


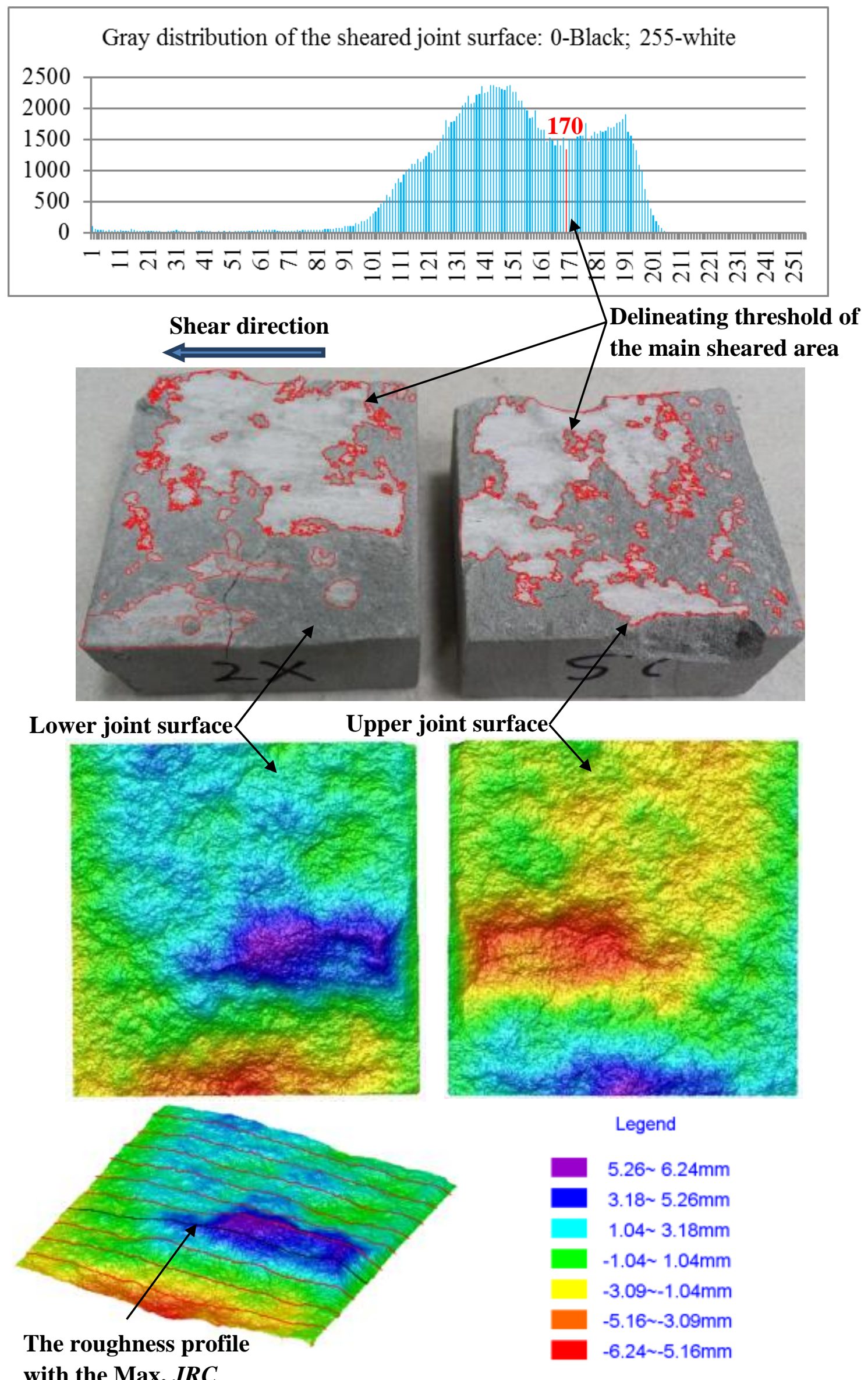

Fig.9 The roughness profile of the main sheared area showed maximum $J R C$ value 


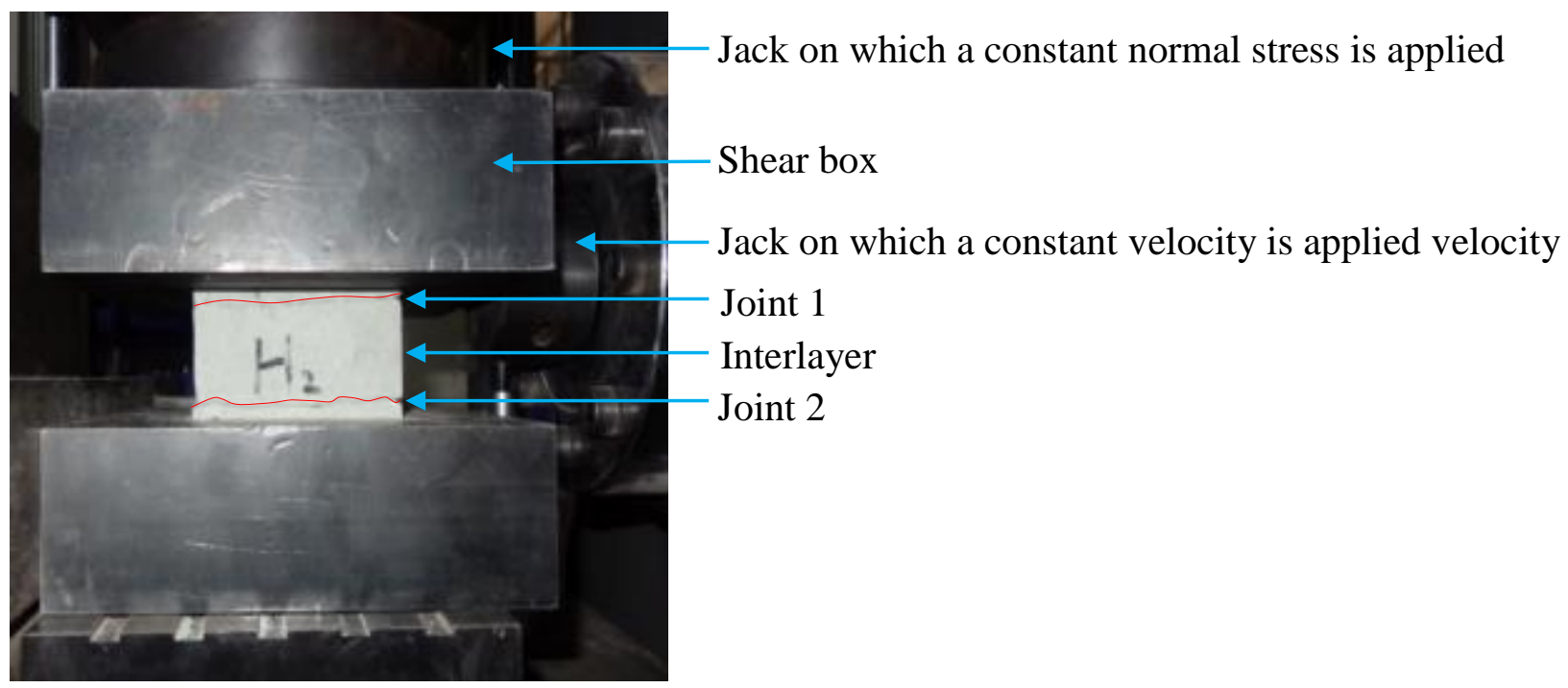

Fig. 10 Experimental configuration of the double-joint shear tests 


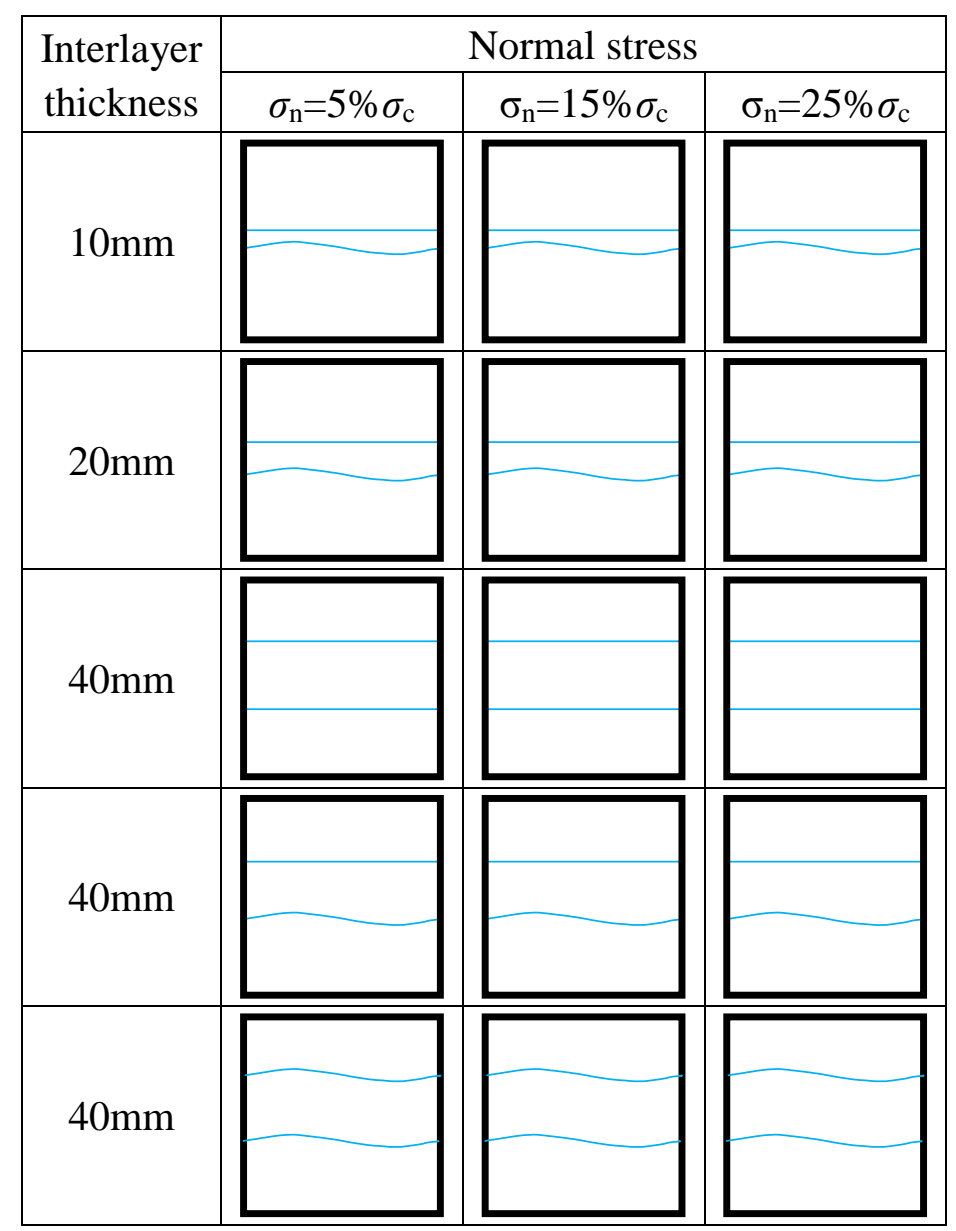

* " " denotes the rock joints generated by Brazilian splitting tests, whose $J R C$ are estimated by using the classified and weighted method; "_ " denotes smooth cleavage joints generated by sawing off, whose $J R C$ are equal to constant value of 0.4 .

Fig. 11 Experimental design of sandstone specimens containing double parallel joints 


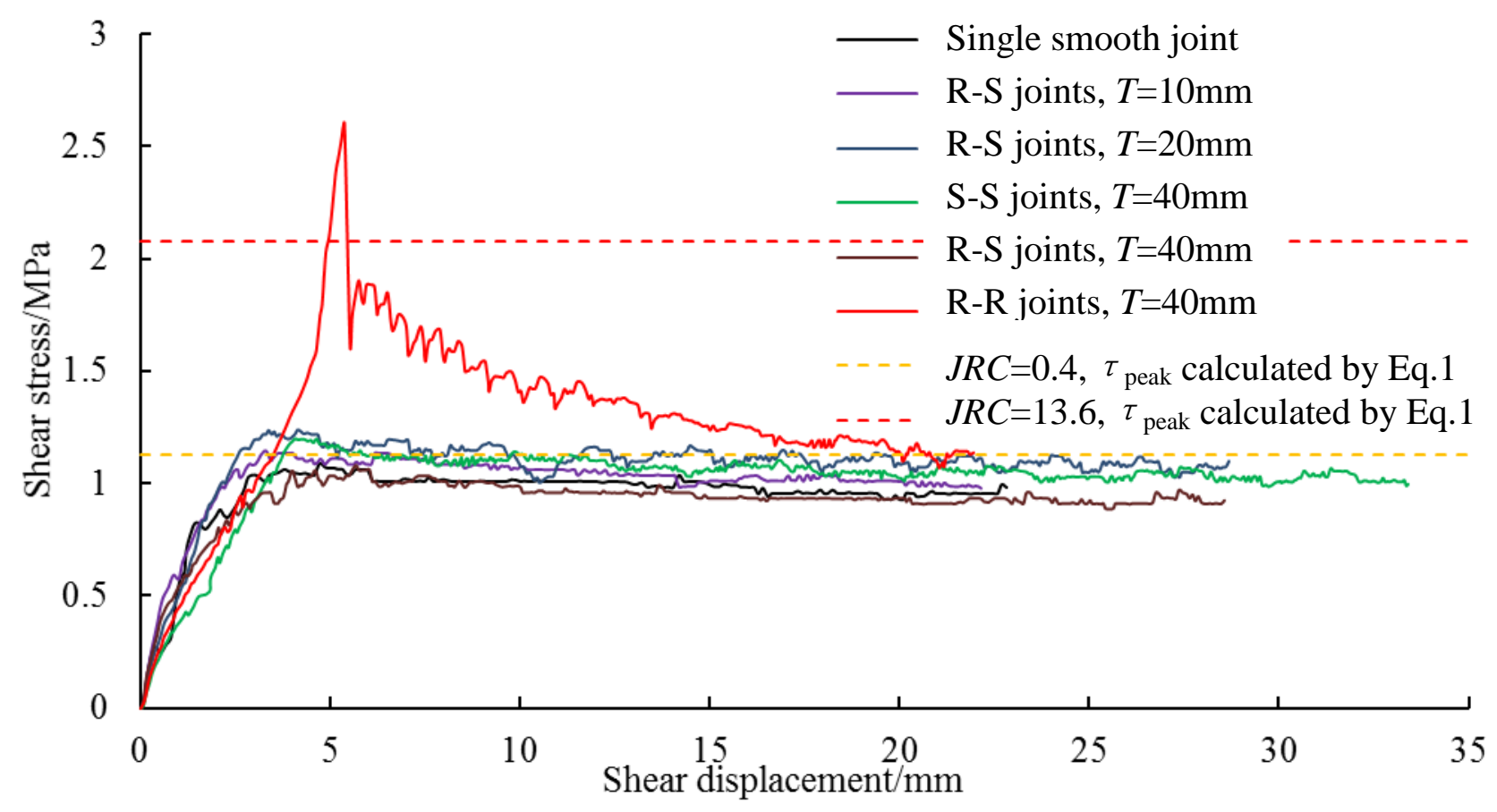

(a) $\sigma_{\mathrm{n}}=5 \% \sigma_{\mathrm{c}}$

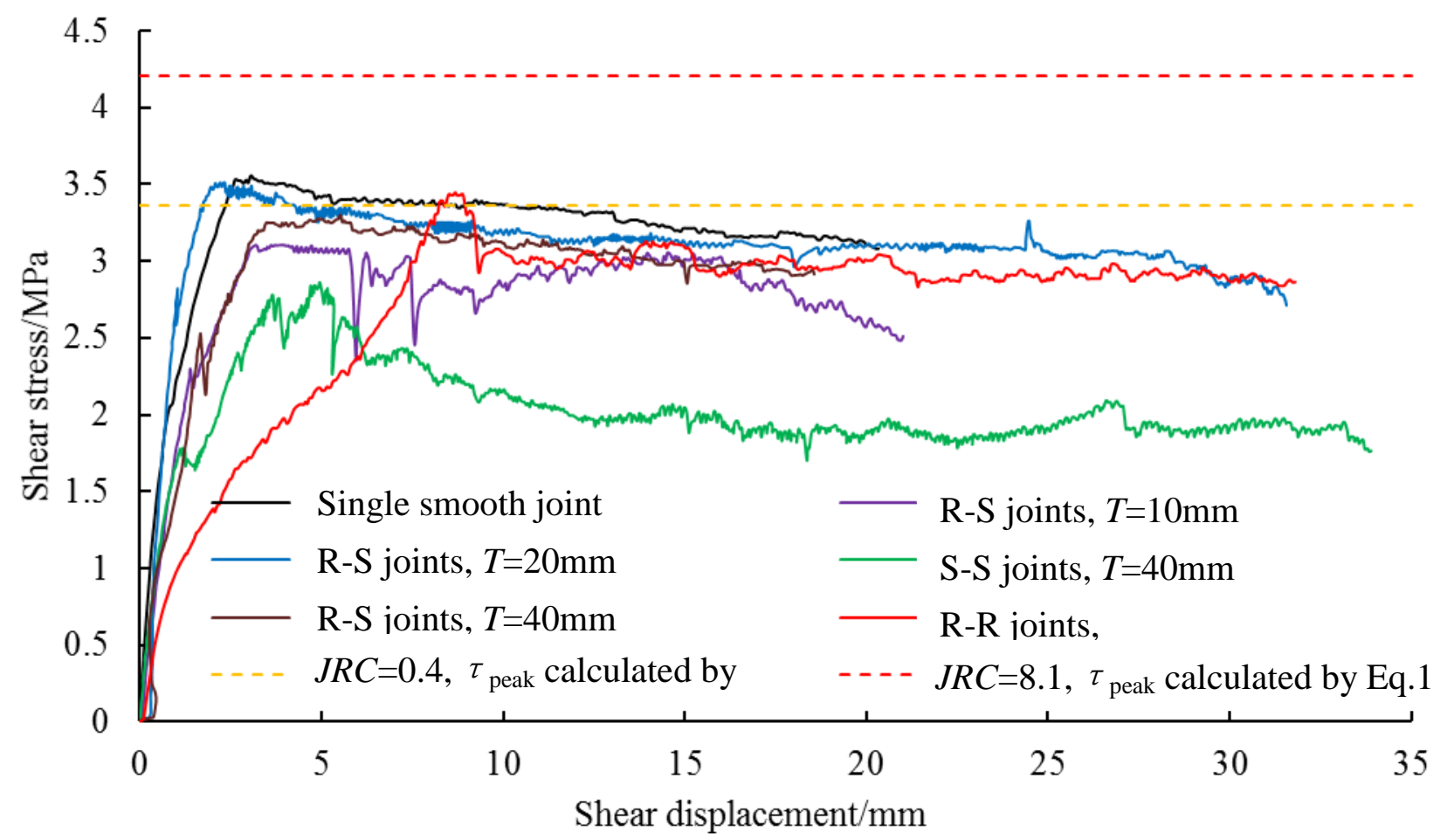

(b) $\sigma_{\mathrm{n}}=15 \% \sigma_{\mathrm{c}}$ 


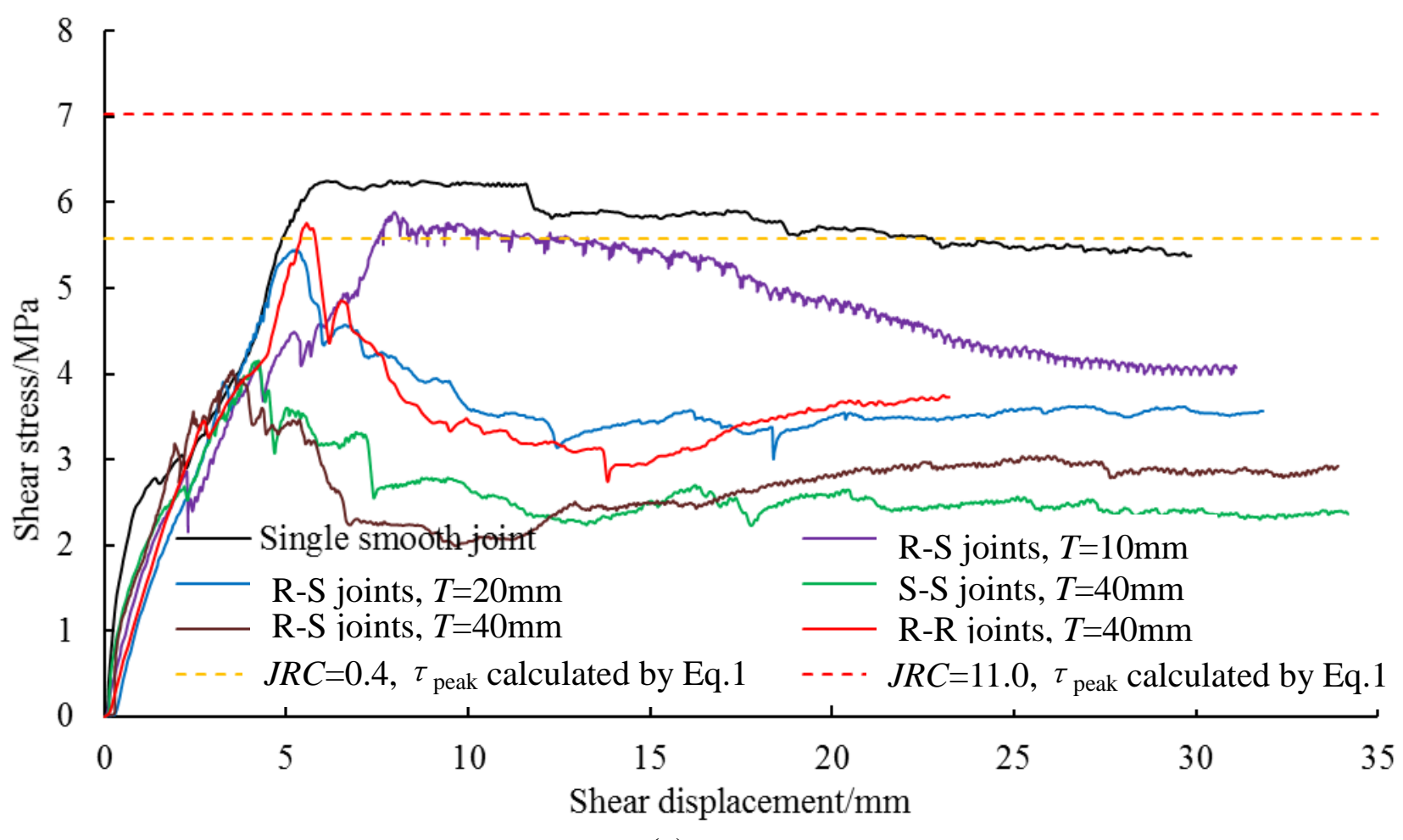

(c) $\sigma_{\mathrm{n}}=25 \% \sigma_{\mathrm{c}}$

Fig. 12 The shear stress - shear displacement curves of double-joint shear tests (a) normal stress $\sigma_{\mathrm{n}}$ $=5 \% \sigma_{\mathrm{c}},(\mathrm{b})$ normal stress $\sigma_{\mathrm{n}}=15 \% \sigma_{\mathrm{c}}$, (c) normal stress $\sigma_{\mathrm{n}}=25 \% \sigma_{\mathrm{c}}$ 


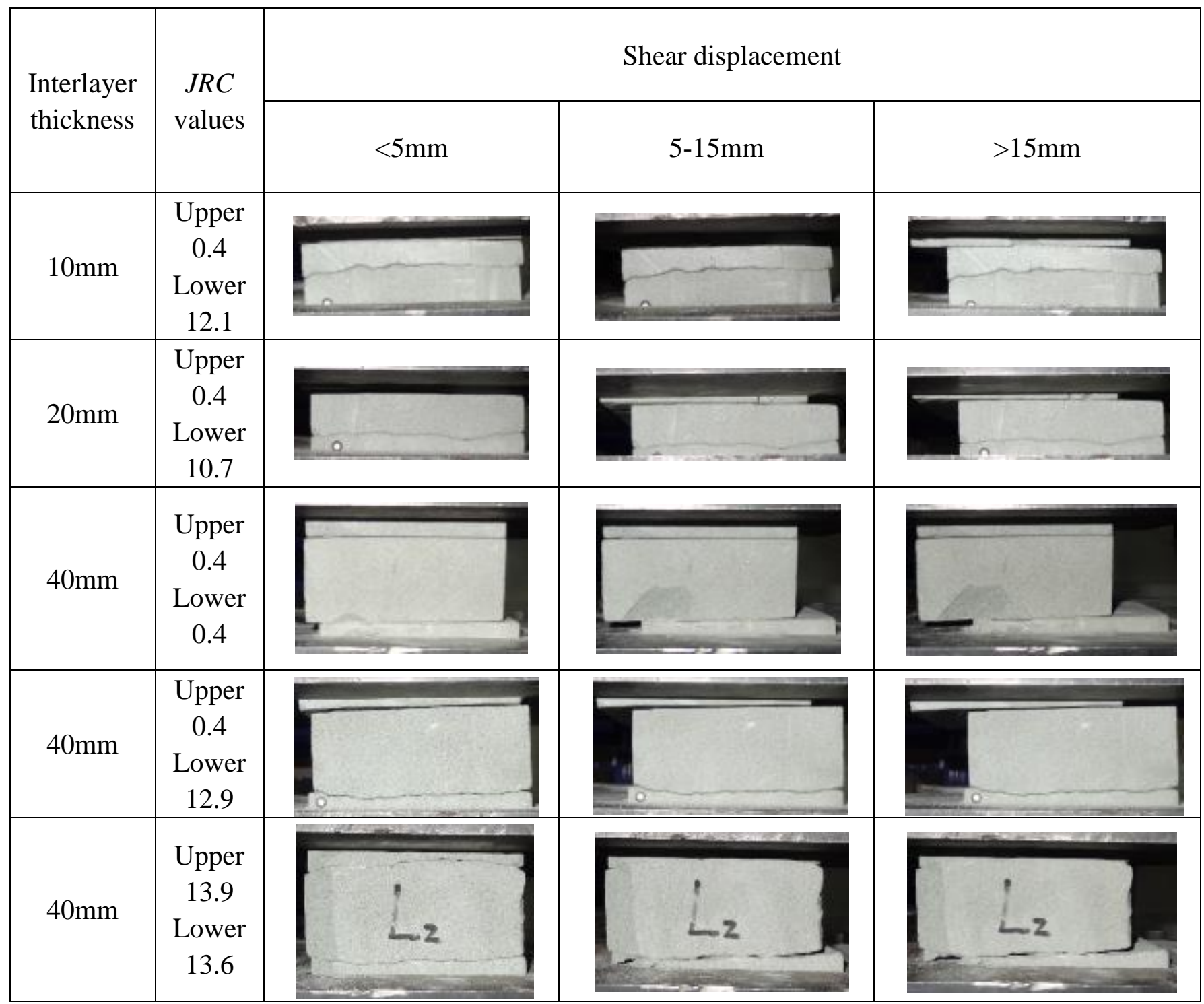

Fig. 13 Failure processes of the sandstone samples during double-joint shear tests under normal stress of $\sigma_{\mathrm{n}}=5 \% \sigma_{\mathrm{c}}$ 


\begin{tabular}{|c|c|c|c|c|}
\hline \multirow{2}{*}{$\begin{array}{l}\text { Interlayer } \\
\text { thickness }\end{array}$} & \multirow{2}{*}{$\begin{array}{c}J R C \\
\text { values }\end{array}$} & \multicolumn{3}{|c|}{ Shear displacement } \\
\hline & & $<5 \mathrm{~mm}$ & $5-15 \mathrm{~mm}$ & $>15 \mathrm{~mm}$ \\
\hline $10 \mathrm{~mm}$ & $\begin{array}{l}\text { Upper } \\
0.4 \\
\text { Lower } \\
10.5\end{array}$ & 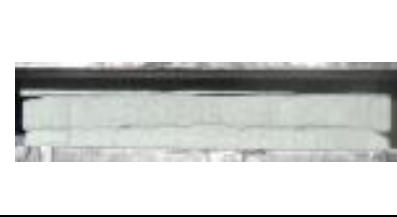 & & \\
\hline $20 \mathrm{~mm}$ & $\begin{array}{l}\text { Upper } \\
0.4 \\
\text { Lower } \\
18.6\end{array}$ & & & \\
\hline $40 \mathrm{~mm}$ & $\begin{array}{l}\text { Upper } \\
0.4 \\
\text { Lower } \\
0.4 \\
\end{array}$ & & & \\
\hline $40 \mathrm{~mm}$ & $\begin{array}{c}\text { Upper } \\
0.4 \\
\text { Lower } \\
12.7\end{array}$ & $=2$ & & \\
\hline $40 \mathrm{~mm}$ & $\begin{array}{l}\text { Upper } \\
10.5 \\
\text { Lower } \\
8.1 \\
\end{array}$ & -1 & & \\
\hline
\end{tabular}

Fig. 14 Failure processes of the sandstone samples under double-joint shear tests under normal stress of $\sigma_{\mathrm{n}}=15 \% \sigma_{\mathrm{c}}$ 


\begin{tabular}{|c|c|c|c|c|}
\hline \multirow{2}{*}{$\begin{array}{l}\text { Interlayer } \\
\text { thickness }\end{array}$} & \multirow{2}{*}{$\begin{array}{c}J R C \\
\text { values }\end{array}$} & \multicolumn{3}{|c|}{ Shear displacement } \\
\hline & & $<5 \mathrm{~mm}$ & $5-15 \mathrm{~mm}$ & $>15 \mathrm{~mm}$ \\
\hline $10 \mathrm{~mm}$ & $\begin{array}{c}\text { Upper } \\
0.4 \\
\text { Lower } \\
12.6 \\
\end{array}$ & & & Woldis: \\
\hline $20 \mathrm{~mm}$ & $\begin{array}{c}\text { Upper } \\
0.4 \\
\text { Lower } \\
13.5\end{array}$ & & & \\
\hline $40 \mathrm{~mm}$ & $\begin{array}{c}\text { Upper } \\
0.4 \\
\text { Lower } \\
0.4 \\
\end{array}$ & & & \\
\hline $40 \mathrm{~mm}$ & $\begin{array}{c}\text { Upper } \\
0.4 \\
\text { Lower } \\
12.5 \\
\end{array}$ & & & \\
\hline $40 \mathrm{~mm}$ & $\begin{array}{c}\text { Upper } \\
0.4 \\
\text { Lower } \\
11.0\end{array}$ & & & \\
\hline
\end{tabular}

Fig. 15 Shear failure processes of the sandstone samples under double-joint shear tests under normal stress of $\sigma_{\mathrm{n}}=25 \% \sigma_{\mathrm{c}}$ 


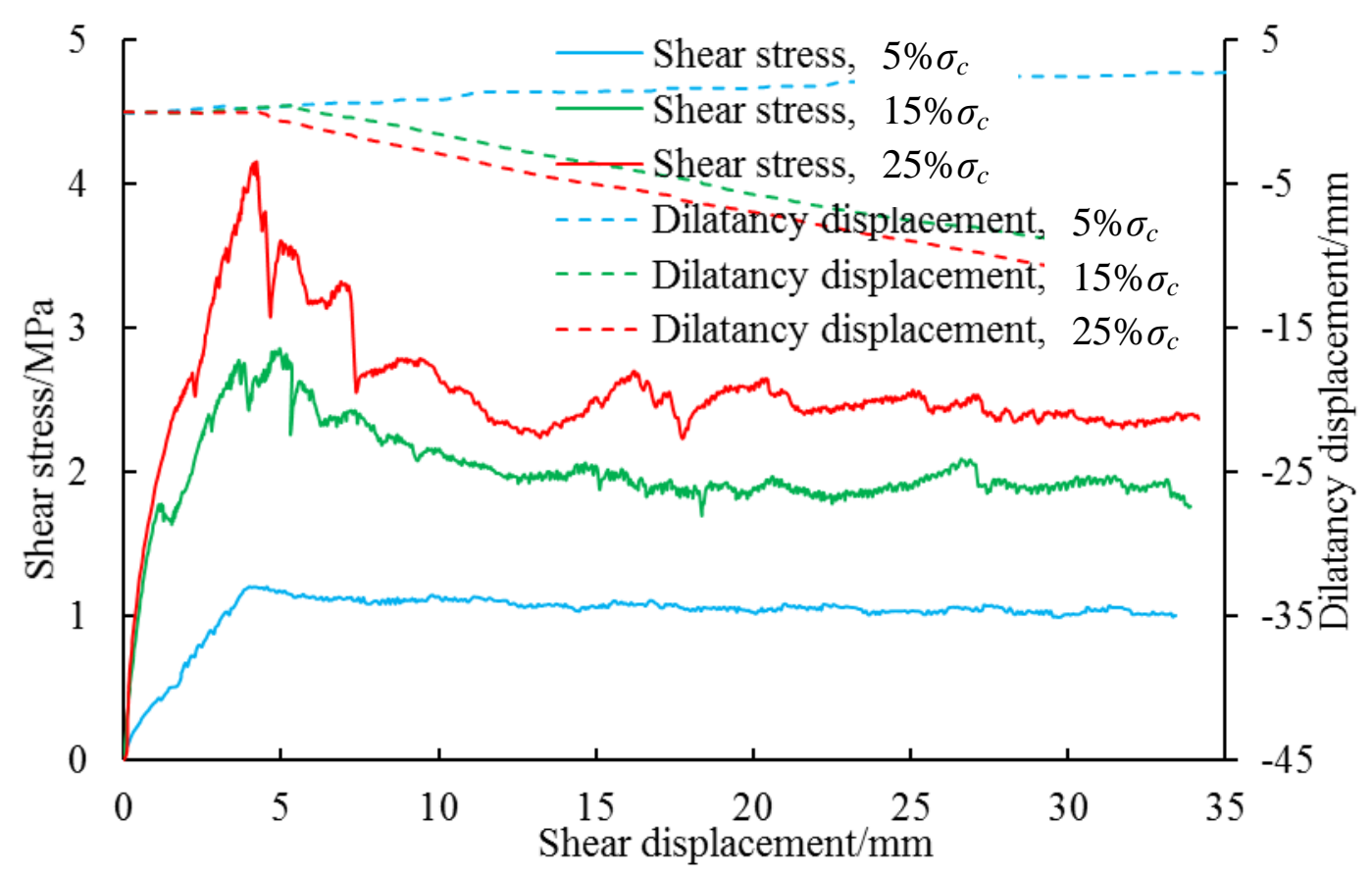

Fig.16 The variation of shear stress and shear dilatancy during the double-joint shear tests 


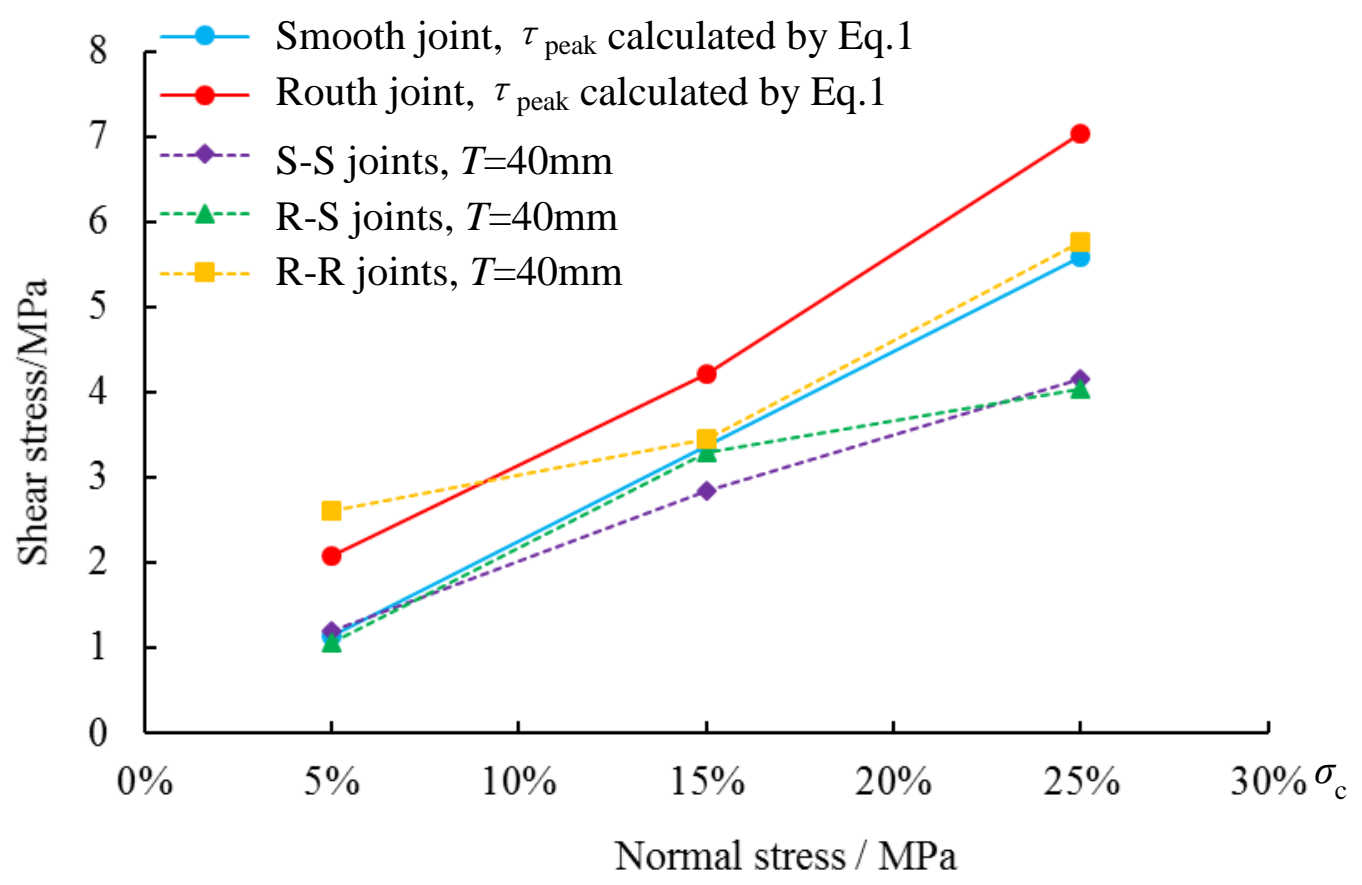

Fig. 17 The influence of $J R C$ on the peak shear strength 


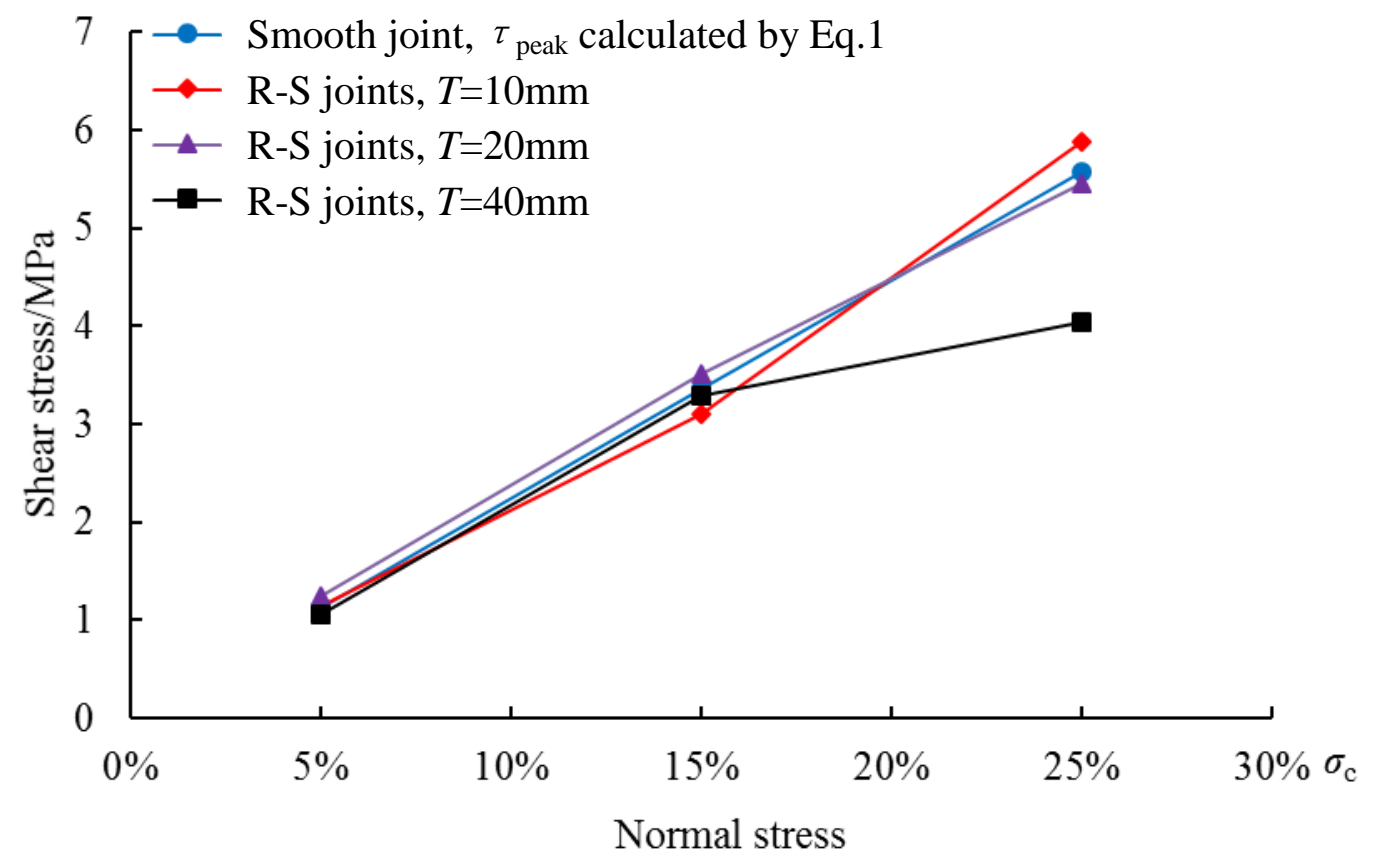

Fig.18 The influence of interlayer thickness on the peak shear strength 